\title{
APROXIMACIÓN A LOS HOSPITALES A TRAVÉS DE LOS REGISTROS DE ACTOS COMUNES DE LA ARCHIDIÓCESIS DE ZARAGOZA
} $(1400-1411)$

\author{
APPROACHING HOSPITALS THROUGH THE REGISTROS DE ACTOS COMUNES \\ OF SARAGOSSA'S ARCHDIOCESE
}

(1400-1411)

Raúl Villagrasa Elías

Universidad de Zaragoza

\begin{abstract}
Resumen: El presente artículo pretende estudiar diferentes menciones de los hospitales a principios del siglo XV. La importancia de los hospitales como instituciones asistenciales se ve reflejada en la documentación eclesiástica y más concretamente en los registros de actos comunes del Archivo Diocesano de Zaragoza. Esta fuente histórica nos ha permitido analizar los ámbitos urbano y rural, la idea del hospitalero y la concesión de indulgencias. Se ha hecho hincapié en el papel de los obispos o arzobispos como garantes de estos establecimientos asistenciales.
\end{abstract}

Palabras clave: hospitales, Aragón, siglo XV, Diócesis de Zaragoza.

\begin{abstract}
The present article attempts an examination of different references to hospitals at the beginning of the $15^{\text {th }}$ century. The importance of hospitals as health care institutions is reflected in ecclesiastical documents and more precisely in the registers of the Episcopal Chancellery (registros de actos comunes) of the Archive of the Diocese of Saragossa. This historical source allows us to analyse the urban and rural areas, the notion of the hospitalero and the sale of indulgences. The article focuses on the role of bishops and archbishops as guarantors of these welfare establishments.

Keywords: hospitals, Aragon, $15^{\text {th }}$ Century, Saragossa's Diocese.
\end{abstract}




\section{Introducción}

Los hospitales nacieron durante los siglos medievales y desde sus primeros momentos fueron considerados una de las principales instituciones asistenciales. De atención y funciones variadas, su principal objetivo fue el cuidado y, a la vez, el control del necesitado. A la variedad de los grupos sociales que en algún momento se alojaron en dichos establecimientos, habría que añadir los múltiples actores privilegiados bajo cuya protección y tutela se desarrolló la red hospitalaria en el Occidente medieval. Desde la alta Edad Media la Iglesia fue la principal protagonista en el amparo de estas instituciones. Los obispos, señores y cabezas de sus respectivas diócesis, fueron clave para su consolidación. Sin embargo, conforme llegó el otoño de la Edad Media, nuevos sectores sociales protagonizaron la conocida laicización de la asistencia hospitalaria. En este sentido, los señores, como el duque de Híjar, las cofradías, como la de San Juan Bautista y Santa María de Villaespesa de Teruel, las autoridades municipales, como el concejo darocense, y la burguesía local, como el adinerado Pedro Poma de Puertomingalvo, fueron algunos de los múltiples patrocinadores conocidos gracias a la historiografía aragonesa.

La destrucción y pérdida de los registros hospitalarios conlleva para el investigador la necesidad de abordar estas instituciones desde múltiples fuentes y perspectivas. Ya en 1974 José Sánchez Herrero proponía determinadas cuestiones que evidenciaban los cambios historiográficos iniciados en aquellas décadas. Por ejemplo, hablaba de la indisolubilidad de las cofradías, las corporaciones de oficios y los hospitales, empresas colectivas que junto a la acción individual, como la donación y la limosna, reflejaban el mundo de la beneficencia, la pobreza y la devoción. Como especialista de la Iglesia y su documentación también advertía la obligación del historiador de acudir especialmente a los archivos catedralicios, diocesanos y parroquiales. De esta forma, se podría paliar las escuetas referencias que proporcionaban los censos y testamentos. Por último, y ya refiriéndonos a los hospitales, Sánchez remarcaba el olvido de aquellos establecimientos fuera de los caminos de peregrinación más importantes, como el que iba a Santiago de Compostela. Su estudio se enmarcaba en las ciudades de la diócesis del río Duero en los siglos XIV y $\mathrm{XV}$, nosotros en cambio tomaremos como observatorio la archidiócesis de Zaragoza en los inicios del siglo XV (Sánchez, 1974: 5-8). ${ }^{1}$

1 Agustín Rubio puso en práctica una panóramica similar al entender la beneficencia como un cúmulo de instituciones con diversos fines y sujetos que atender. En su caso, presentó su estudio partiendo de 
La historia de los hospitales aragoneses ha estado siempre en conexión con la sanidad, la caridad, la pobreza y la marginación, temáticas que recibieron un importante impulso a partir de 1980, con motivo del empuje de la historiografía francesa desde las dos décadas anteriores. ${ }^{2}$ A las aproximaciones de historia general de la primera mitad del siglo XX, centradas en el hospital de Nuestra Señora de Gracia de Zaragoza, ${ }^{3}$ les siguieron un aumento y diversificación investigadora. Un primer foco, todavía activo, fue la Facultad de Medina de la Universidad de Zaragoza, en donde destacó la figura de Asunción Fernández Doctor. ${ }^{4}$ Otro campo académico fue la arqueología, gracias a la cual vieron la luz los yacimientos de Santa Cristina de Somport ${ }^{5}$ y Benasque. ${ }^{6}$ Finalmente, el medievalismo comenzó a fijarse también en los hospitales como una temática de estudio.

La década de 1980 quedó inaugurada con los estudios de María Isabel Falcón. Esta autora demostró cómo al aunar los registros del Archivo de la Corona de Aragón con la información extraída del Archivo Municipal de Zaragoza se obtenía una amplia panorámica del tejido hospitalario de la ciudad de Zaragoza (Falcón, 1980: 183-226). Sobre la aljama hebraica de esta misma ciudad, Asunción Blasco utilizó protocolos notariales para estudiar los sistemas asistenciales en donde las cofradías y los hospitales se convirtieron en actores protagonistas (Blasco, 1989: 227-236 y 1990: 3-46 y 265-288).

En la década de 1990, María Luz Rodrigo tomó como referencia nuevamente los protocolos notariales y la documentación municipal para conocer el ejercicio de la caridad en una ciudad como Daroca (Rodrigo, 1995: 287-318). Por otro lado, contamos con los trabajos de María Teresa Iranzo, conocedora

la particularidad de Valencia, ciudad conquistada en 1238, momento en el que se impuso un nuevo sistema social y por tanto, un nuevo entramado asistencial (Rubio, 1997: 15-60). Por la cercanía temática, espacial y documental con este artículo es de obligada lectura el trabajo de Esparza (2001-2002: 91-128).

2 Para un mayor acercamiento de fuentes e historiografía vid. Gallent (1996: 179-191), Navarro (2001: 337-346) y Rubiolo (2004: 193-206).

3 Gimeno, 1908; Muñoz, 1944: 143-166; Baquero, 1952; Dolset, 1955: 13-19; Zubiri, 1972.

4 A la tesis publicada de Asunción Fernández Doctor le siguen trabajos derivados de otras tesis doctorales, ya como directorada: Fernández, 2000; Blasco, 2008; Arcarazo y Lorén, 2000 y Arcarazo, 2010. De reciente elaboración: Blasco, 2014 (tesis doctoral inédita).

5 Para no saturar al lector con las campañas arqueológicas de Santa Cristina del Somport acúdase a la revista Arqueología aragonesa $(1988-1989,1990,1991)$. Por otro lado, Santa Cristina de Somport ha sido estudiado también por su importancia para el peregrino y por su cartulario: Ubieto, 1966: 267-276; Durián, 1986; Kiviharju, 1991 y 2004; Domingo, 2001: 285-313.

6 La culminación de las excavaciones en Benasque y su puesta en relación con los hospitales franceses de la zona se puede consultar en Ona y Calastrenc, 2009. 
de la leprosería de Huesca y del hospital nobiliario de la villa de Híjar (Iranzo, 1995: 467-482 y 1997: 105-124). Desde el punto de vista documental, las ordinaciones dispuestas por el duque de Híjar son una fuente excepcional. Éstas servían para regir internamente la institución, y aunque la práctica pudiera desviarse, muestran claramente las intenciones y la mentalidad de las elites sociales que patrocinaban los hospitales. Otro magnífico ejemplo al respecto son las ordinaciones que otorgó don Alonso de Aragón al hospital de Nuestra Señora de Gracia de Zaragoza y que editó Cristina Monterde. Gracias a ellas se puede reconstruir perfectamente el organigrama institucional de un hospital general (Monterde, 2008: 505-528).

Respecto al hospital de San Juan Bautista y Santa María de Villaespesa de Teruel, administrado y financiado por la cofradía homónima, y estudiado por Germán Navarro, la fuente utilizada fue un libro padrón del notario Alfonso Jiménez (1481-1518). En él se recogen múltiples facetas del establecimiento gracias a su contenido: un inventario, una relación de préstamos censales y una lista de los legados píos (Navarro, 2000: 565-590). De forma similar, María Lidia Buompadre se centró tanto en los testamentos y las diferentes mandas piadosas para instituciones caritativas y grupos sociales necesitados, como en el también registro de censales del hospital de Puertomingalvo (Buompadre, 2000: 67-88.) Terminamos este repaso haciendo mención del reciente trabajo de historia comparada de Cristina Pérez, quien pone de manifiesto las características de los hospitales generales aragoneses (Pérez, 2013: 291-305).

Como ya hemos dicho, al impulso institucional e inicial de la Iglesia le siguió un proceso de laicización. Al patrocinio eclesiástico se sumó la acción de la nobleza, la burguesía, las cofradías y los gobiernos municipales a partir del siglo XIV. La centuria siguiente supuso además la consolidación de la red de hospitales aragonesa, tanto en el mundo urbano, con el nacimiento de los primeros hospitales generales, como en el mundo rural (Villagrasa, 2013-2014). Sin embargo, a pesar de todo lo mencionado - la entrada de nuevos patrocinadores laicos y los cambios en la red hospitalaria - , la Iglesia mantuvo una activa promoción institucional. Muestra de ello fue la favorable actuación de los arzobispos zaragozanos con respecto a los hospitales, tanto de su diócesis como de otras.

El obispado zaragozano se creó durante el siglo XII, a raíz de las conquistas territoriales de la monarquía aragonesa. Su dominio se centraba en el valle del río Ebro y se extendía por todo el sur del reino de Aragón. Sus límites chocaban con los de la diócesis de Pamplona en las Cinco Villas, con la diócesis de Tara- 
zona y con la de Sigüenza. Por último, las de Albarracín y Teruel restaron parte de su territorio con sus fundaciones a finales del siglo XII y del siglo XVI, respectivamente. Fue a partir de 1318 con la bula del papa Juan XXII cuando Zaragoza se convirtió en sede metropolitana. La archidiócesis de Zaragoza dominó eclesiásticamente gran parte del reino y otros territorios circundantes al tener como sufragáneas las diócesis de Huesca, Tarazona, Pamplona, Calahorra y Segorbe-Albarracín (Buesa, 1991: 29-68 y Ubieto, 1983: 41-51). ${ }^{7}$

Nuestro objetivo no es otro que el de analizar las referencias sobre hospitales contenidas en los registros de actos comunes durante los últimos once años del pontificado de don García Fernández de Heredia (1383-1411) (Serrano, 2002-2003: 197-246 y 2004-2005: 87-97), fuente emanada por la cancillería episcopal cesaraugustana y custodiada en el Archivo Diocesano de Zaragoza. Nuestra aportación se fundamenta en una cata basada en los trabajos previos de la profesora Pilar Pueyo y del antiguo archivero de la institución, José Antonio Lasarte López (Lasarte, 2002 y 2003). La mayoría de la documentación trabajada se añade transcrita en las últimas páginas.

\section{La supervisión eclesiástica}

La documentación eclesiástica ha aportado siempre una magnífica cantidad de información sobre los hospitales. Su tipología es bastante amplia, así como la propia organización y jerarquía interna de la Iglesia. ${ }^{8}$ Para el caso que nos ocupa, el agente productor de la documentación fue la cancillería episcopal. De ella emanaban tres tipos de fuentes realmente útiles para la historia de los hospitales: los registros de actos comunes, las visitas pastorales y las visitas ad límina. ${ }^{9}$ En esta ocasión, hemos seleccionado los registros de actos comunes (Pueyo, 2001: 701-713).

$7 \quad$ Véase el mapa 1.

8 Para conocer mejor tanto la historia de los hospitales y su relación con la archivística, así como otras instituciones o actividades asistenciales, son de obligada consulta las actas del XI Congreso de la Asociación de Archiveros de la Iglesia en España, celebrado en Valencia en 1995 y recogidas en los número 10 y 11 de Memoria ecclesiae. A modo de ejemplo y por su relación con estas líneas en las que tratamos hospitales en una determinada diócesis, consúltense: Iglesias, 1997: 119-125 y Hevia, 1997: 127-149.

9 Las dos últimas fuentes guardan entre sus líneas tanto fragmentos dedicados en exclusiva a la administración y situación de los hospitales como pequeñas referencias. En ocasiones, la cantidad y el tamaño de estas referencias documentales varían en función del gobierno y la importancia de la institución. Así, una buena gestión de las rentas y una óptima atención pasaban desapercibidos frente a una hacienda en ruinas y una continua irresponsabilidad, ante las que los obispos y sus visitadores debían intervenir. 
Puede variar su nombre en otros archivos, pero su forma y contenido se mantienen en otros lugares. Los registros de actos comunes recogen, en sus 178 volúmenes, la documentación que emanaba cada día de la cancillería episcopal. Por tanto, en los casos que se conservan largas series suponen una fuente de gran importancia. Pilar Pueyo estableció una tipología para los primeros registros conservados, los del pontificado de Pedro de la Jugie (13451347). Dicha autora estableció la siguiente tipología temática: 1) concesiones de tonsura y ascensos; 2) el beneficio eclesiástico; 3) permisos para reparar edificios religiosos, para enterramientos y donaciones; 4) licencias para pedir limosnas, en ocasiones para redimir cautivos; 5) documentos judiciales; 6) hacienda; 7) aquello relacionado con el papel que ejercía el arzobispo como señor feudal; y por último, 8) documentos varios (Pueyo, 1989: 523-536). Obviamente una serie documental de tan larga duración, desde 1345 hasta 1879 , varió su tipología durante los siglos. El interés radica propiamente, tanto para el medievalista como para el modernista, en las posibilidades que ofrecen estos documentos para reconstruir una historia social y de las mentalidades de la Iglesia y la sociedad de su tiempo (Royo, 2000: p. 538). ${ }^{10}$

Para los siglos medievales ha sido precisamente la profesora Pueyo quien ha realizado diversas aproximaciones diplomáticas e históricas sobre los registros de actos comunes de la cancillería episcopal zaragozana, profundizando también en el conocimiento de la diócesis, sus arzobispos y su curia. Los primeros trabajos de la autora se enmarcaban cronológicamente en los años centrales del siglo XIV o lo que es lo mismo, los cortos pontificados de los dos primeros arzobispos cesaraugustanos: Pedro de la Jugie (1345-1347) y Guillermo d'Aigrefeuille (1347-1450). El tercero en ocupar el arzobispado, durante un periodo mucho más prolongado, fue Lope Fernández de Luna (1352-1380) y su sucesor, el cuarto prelado, García Fernández de Heredia (1383-1411). ${ }^{11}$ En el presente artículo nos moveremos sobre los registros de actos comunes de este último arzobispo y a lo largo de la primera mitad del siglo XV.

Durante los últimos años del siglo XIV y la primera mitad del siglo XV la red de hospitales se consolidó en el mundo rural. Anteriormente existían ya establecimientos en este contexto, normalmente en conexión con monasterios

10 Los registros de decretos complementaron en época moderna a los registros de actos comunes (Lozano, 1981: 61-66).

11 Como muestra de los múltiples aspectos que trataba la archidiócesis zaragozana citamos las referencias de algunos trabajos de Pilar Pueyo Colomina: 1991: 269-312; 1993: 705-736; 1997: 355-366; 2000: 401-431; 2003: 769-788; 2005: 799-862; у 2008: 635-660. 
o principales vías de comunicación. A partir de esta época las primeras menciones de hospitales, pero sobre todo, las fundaciones aparecen con mayor asiduidad. Veamos los ejemplos de Rubielos de Mora (1384), Alquézar (1402), Tamarite de Litera (1414) o Puertomingalvo (1430). Son casos de villas y lugares de tamaño medio donde los hospitales llegaron tardíamente con respecto al mundo urbano que contaba con estas instituciones ya en el siglo XII (Villagrasa, 2013-2014: 108-116).

Como es lógico, los arzobispos zaragozanos fueron responsables de buena parte de la actividad hospitalaria y caritativa, cuya función era aliviar la situación de los pauperes Christi. En su figura se encomendaba la tarea de supervisar especialmente los hospitales que dependían de las parroquias e iglesias de su diócesis. ${ }^{12}$ La atención prestada llegaba a través de indulgencias, limosnas, licencias, privilegios, donaciones y la supervisión, que la mayoría de las veces se daba a través de las visitas pastorales.

Su función era en muchas ocasiones similar a la actividad que podía tener el Papa. En los bularios de Benedicto XIII, conocido como el Papa Luna, hay numerosas menciones a hospitales dentro y fuera de Aragón. La forma de otorgar protección y apoyo a estas instituciones fue a través de la concesión de indulgencias y privilegios, como el hospital darocense que había sido fundado por Juan de Román a finales del siglo XIV. Debido a su estado ruinoso en 1398 Benedicto XIII concedía un año y cuarenta días de indulgencias para aquellos fieles que ayudaran a este hospital de pobres (Cuella, 2006: 362).

La promoción de instituciones asistenciales viene de tiempo atrás, al igual que en el resto de territorios europeos. Las primeras noticias las recopiló Antonio Ubieto cuando mencionaba el papel del obispo García (1076-1086), quien instituyó la Casa de la Limosna en la catedral de Jaca (Ubieto, 1983: 20-21). Su homólogo en el catedral de Pamplona prometía indulgencias a todo aquel que ayudara a la construcción del hospital de San Miguel en Uncastillo (Goñi, 1965: 432-433). Ya en el siglo XV los obispos ilerdenses también visitaban los hospitales parroquiales para anotar su situación. Es el caso de los hospitales de Fraga y Monzón que en 1445 aparecen mencionados y descritos en la correspondiente visita pastoral (Castillón, 1995: 101 y 105).

12 Al respecto de las parroquias véase Royo, 1993: 43-63. Por tro lado, el papel de un arzobispo zaragozano como garante de la caridad ha sido ya estudiado: Miguel, 1997: 115-128. 
Para el caso que nos ocupa, los arzobispos zaragozanos desarrollaron acciones similares con los hospitales dentro de su diócesis. Un magnífico ejemplo de la refundación hospitalaria en Aragón fue el proceso de Alcañiz. En dicha ciudad los cuatro hospitales parroquiales, alguno administrado por los jurados, unieron sus patrimonios y esfuerzos en una sola institución. De esta manera nació el hospital de San Nicolás de Bari en 1418, gracias a la aprobación del arzobispo zaragozano Alonso de Argüello (Blasco, 2000-2002: 145146).

La consulta de la Historia Eclesiástica de Diego de Espés muestra nuevamente la preocupación de los prelados por estas instituciones, así como la importantísima acción individual de múltiples clérigos. Este último caso queda ejemplificado con la labor de fray Benedicto de Olmedo, franciscano que en 1387 reedificó el hospital para pobres y viandantes de Tiermas. Situado en el camino entre Jaca y Navarra, Tiermas supuso desde antaño una importante puerta de acceso entre estos dos territorios, caracterizado por los baños termales que dan nombre al establecimiento. Dos años después, en 1389, los vicarios generales, encargados del arzobispado en ausencia de García de Heredia, exhortaban a los fieles que con sus limosnas ayudaran a la iglesia de San Pablo y al hospital de San Blas de Zaragoza. Presente ya García de Heredia, y encontrándose el 4 de noviembre de 1401 en la villa de Caspe, aprobó la iniciativa de don Jordán Pérez de Urries, Gobernador de Aragón. Éste quiso dejar en su testamento dinero para construir una capilla en honor a San Cristóbal en el hospital del lugar. Finalmente, la caridad no giraba únicamente en relación a los hospitales. Habiendo llegado el arzobispo en esta ocasión a Cariñena, ratificó las buenas obras llevadas a cabo por los oficiales del concejo. Aportando una de sus principales herramientas de persuasión, García de Heredia ofreció cuarenta días de indulgencias para quienes ayudaran a alimentar a las doncellas pobres y huérfanas los domingos y días de fiesta. ${ }^{13}$

De 1435 es la visita pastoral que se encontró en el Archivo Diocesano de Zaragoza. Se trata del documento más antiguo en sus características para la archidiócesis cesaraugustana. Fue encargada por Dalmau de Mur y Cervellón

13 Archivo Capitular de la Seo de Zaragoza (ACSZ), ed. facsímil, Historia eclesiástica de la Ciudad de Zaragoza desde la venida de Jesú Christo Senyor y Redemptor nuestro hasta el anyo de 1575, escrita por Diego de Espés, ff. 576r, 577r, 585v, 585r, respectivamente. Los registros de actos comunes trabajados también recogen algunas de estas noticias. Es el caso del hospital de Tiermas y el de San Blas de Zaragoza: Archivo Diocesano de Zaragoza (ADZ), Registros Actos Comunes (RAC), t. I (1385), ff. 362v-363r; y t. VI (1407-1408), ff. 57v-58r. 
y contiene información sobre Valderrobles y la región. En ella, los visitadores acudieron al hospital de la villa. El registro que dejaron del inmueble fue la necesidad de reparar algunas partes del edificio, así como llevar una mejor administración de las rentas y censos que tenía el hospital. Los visitadores instaron a los jurados a que utilizaran un libro para mejorar la contabilidad (Gil, 1995: 216).

El buen conocimiento de las rentas de una institución era un elemento básico para su correcto desarrollo. Una y otra vez, las diferentes visitas pastorales repetían encarecidamente a jurados y hospitaleros la importancia de los libros de contabilidad. En el siglo siguiente el problema de la mala administración seguía presente. La diócesis oscense reiteró la misma cláusula en la visita pastoral de 1572 en los hospitales de Castejón de Monegros y Alcubierre:

Mas mandamos que dentro de ochos dias continuos los jurados y obrero del dicho hospital deste lugar compren un libro blanquo de quatro manos en el qual sean asentados todas las rentas del dicho hospital y toda la hazienda que tiene y dende adelante tendra, asi de limosnas como de lexos y otros legados pios de dineros, panes, cafranes y otras mandas y que en cada un annyo dichos jurados con el vicario del presente lugar hayan de tomar la cuenta al obrero del dicho hospital de recepta y gasto y quando venga la visita a este lugar les mandamos hayan de dar con dicho libro la cuenta de dicho hospital al visitador... ${ }^{14}$

\section{Respuestas ante el estado ruinoso}

Entre los registros de actos comunes que se guardan en el Archivo Diocesano de Zaragoza podemos encontrar diferentes tipos de documentos que hacen mención de los hospitales. En general, la mayoría de las noticias nos hablan del mal estado de algunos edificios, lo que llevaba al arzobispo y, en ocasiones, a los vicarios generales, a tomar cartas en el asunto. En segundo lugar, algunos documentos mencionan a los hospitaleros y acciones derivadas de su profesión. Y por último, encontramos múltiples privilegios otorgados a los hospitales, dados en forma de licencias, normalmente con indulgencias.

$\mathrm{Al}$ igual que las visitas pastorales reflejaban el mal estado o la inadecuada administración de los hospitales, algunos documentos insertos en los registros de actos comunes siguen la misma línea. Es el caso del hospital de Fuendeto-

14 Archivo Diocesano de Huesca, Visita Pastoral (VP) 1.2.1/01.03 (1572), ff. 12r y 20r. 
dos y la breve licencia que concedió el arzobispo García Fernández de Heredia en 1405. El antiguo hospital se encontraba en un estado de auténticas ruinas debido a una penosa gestión. Al ser el destinatario los jurados del lugar de Fuendetodos hemos de entender que la responsabilidad era suya. Éstos quedaron encargados de vender el solar del antiguo hospicio para que cuanto antes se reanudaran las obras del nuevo edificio. ${ }^{15}$

Tres años después, en 1408, ocurrió una situación similar en otras dos poblaciones. En la ribera del Jiloca, al sur de la ciudad de Daroca, se encontraban Burbáguena y San Martín del Río. En ambos casos el arzobispo tuvo que recordar a los jurados la necesidad de alojar a los pobres de Cristo. Los jurados de Burbáguena recibieron el encargo de reconstruir el hospital y sus habitaciones, o si lo preferían, de habilitar las estancias cercanas a la iglesia de San Miguel o acondicionar su capilla, para de esta forma poder recibir a pobres y peregrinos. ${ }^{16}$ En cambio, en la localidad de San Martín del Río, el problema parece ser que no era de los jurados. Con motivo de una visita pastoral realizada previamente quedó patente la miseria del inmueble. Debemos suponer que la administración no era municipal - quizás eclesiástica - , ya que Juan Boecio, en nombre del arzobispo, donó la institución a las autoridades públicas. ${ }^{17}$

En el cercano lugar de Báguena los hospitales también estaban escasos de recursos. En este caso el arzobispo zaragozano tuvo que utilizar un elemento diferente, las indulgencias. Con ellas los fieles redimían la pena temporal de sus pecados gracias a las limosnas para el hospital y ermita de Báguena. El beneficio por tal esfuerzo eran cuarenta días (Bureta, 2003: 27-28). ${ }^{18}$ Más adelante nos detendremos en la relación entre indulgencias y hospitales.

No lejos de allí, en Muniesa, se localizó otro edificio de características similares. El encargado de ponerlo en marcha fue Simón Acenari, vicario de la vecina localidad de Cortes. Parece que la iglesia de Santa María no podía cubrir las necesidades asistenciales del lugar. García de Heredia consideró que al menos se necesitaban seis lechos para el hospital. ${ }^{19}$ Meses más tarde, la archidiócesis zaragozana volvía a ponerse en contacto con Simón Acenari para recordarle su obligación de decir misas por el alma de dos personas. Y es que

15 ADZ, RAC, t. V (1405-1406), f. 55r-v.

16 ADZ, RAC, t. VI (1407-1408), f. 349r.

17 ADZ, RAC, t. VI (1407-1408), f. 314v.

18 También en conexión a las múltiples ermitas de Villarquemado estaba el hospital del lugar, recientemente edificado (ADZ, RAC, t. III (1400-1401), ff. 62v-63r).

19 ADZ, RAC, t. 7 (1409-1411), f. 349r-v. 
Domingo Serrano y su difunta esposa, Benedicta, cedieron en sus testamentos las casas donde se instauró el hospital. Además, para su mantenimiento, dejaron unas rentas anuales de diez sueldos y ocho dineros jaqueses, destinados por el arzobispo para la manutención y reparación del hospital. ${ }^{20}$ En años posteriores, los testamentos que se conservan dan prueba de otras mandas testamentarias de los vecinos y lugareños, quienes dejaban dinero en metálico o mobiliario y ropa de cama. En un testamento de 1457, perteneciente a Bartolomé de la Gueruela, fueron donados cien sueldos jaqueses para el «hospital del conçello», recientemente edificado cerca de la iglesia (Iturbe y Lorenzo, 2010: 149). Si nos remitimos a los documentos que hemos visto hasta ahora, posiblemente ocurrió en Muniesa un proceso similar al de San Martín del Río. Es decir, el pequeño hospital rural pudo caer en desgracia por una mala administración - bien eclesiástica, bien municipal-, lo que llevó a la ruina del edificio. En 1457, tal como nos dice el testamento de Bartolomé, el hospital fue reedificado o reparado, quedando ya en manos de los jurados. ${ }^{21}$

De los mencionados documentos se pueden extraer una serie de características. Primeramente, la responsabilidad directa recaía sobre los jurados, es decir, sobre el municipio y los probis hominis. En todos los ejemplos que hemos visto el arzobispo y su curia se dirigían a los jurados, lo que muestra la creciente municipalización del mundo rural. Los casos de San Martín del Río y Muniesa son más que evidentes. En la primera, la propia institución es donada a los jurados de San Martín del Río, mientras que en la segunda, los propios testamentos enlazan el hospital con el concejo. Por último, destaca su carácter ruinoso y la continua y mala administración.

Exceptuando Fuendetodos, la totalidad de los municipios referidos hacen mención de la Comunidad de aldeas de Daroca. Este tipo de organización del mundo rural, tan típico de la Extremadura aragonesa, se dividía internamente en sesmas. Aquella situada más al este era la sesma de Honor de Huesa. En ella además de Muniesa, existieron hospitales en Blesa y Cortes de Aragón. No muy lejos se encontraba también Oliete, con María la hospitalera. La sesma de Gallocanta era una de las que por el momento sabemos que disponían de un gran número de instituciones: Retascón, Manchones, Murero, Bello, San Martín del Río y Báguena (Villagrasa, 2013-2014: 85-91).

20 ADZ, RAC, t. VII (1409-1411), ff. 380v-381r.

21 Otro ejemplo de la ruina del hospital y la consecuente reparación también se dio en Aguilón, localidad cercana a Fuendetodos: ADZ, RAC, t. VII (1409-1411), f. 384v. 


\section{Sobre los hospitaleros}

Dentro de los registros de actos comunes del Archivo Diocesano de Zaragoza algunos de los documentos atañen a la labor de los hospitaleros. En este caso el número de referencias es menor, tan sólo dos, y se centran sobre dos establecimientos urbanos: uno en Daroca y otro en Zaragoza. Antes de adentrarnos en ellos conviene conocer la figura de los hospitaleros.

Más allá de una definición sencilla, «persona encargada del cuidado de un hospital», ${ }^{22}$ es complicado acotar el termino hospitalero. Se puede decir que eran aquellas personas, tanto hombres como mujeres, que trabajaban diariamente en estos establecimientos. En la mayoría de los casos el varón ejercía el cargo de hospitalero y residía en el edificio junto a su mujer e hijos. De esta forma, el hombre atendía a los pobres y enfermos de su mismo sexo mientras que la mujer auxiliaba a las féminas. En general, los hospitaleros se encargaban de la limpieza, abastecimiento y especialmente, de la asistencia y recepción de los necesitados. Dependiendo de la tipología y contexto del hospital estos trabajadores tenían unas funciones u otras. Así, el hospitalero de Benasque, debido a su situación en alta montaña, debía enterrar a aquellos caminantes que fallecieran en la travesía. El hospital cercano de Gistaín tenía un trabajador que vendía vino y viandas a los que se hospedaban. De la misma manera, no era igual la asistencia que proporcionaban hospitaleros y hospitaleras en las pequeñas instituciones que en los grandes establecimientos urbanos, donde a finales del siglo XV y principios del XVI habían quedado realizando la labor de meros conserjes.

Una de sus funciones giraba en torno al control de los marginados. Los hospitales, más allá de su carácter caritativo, han sido calificados por la historiografía como centros de control social, en donde prostitutas y maleantes podían interactuar con los verdaderos necesitados o pauperes Christi. Un buen ejemplo de ello son las ordenanzas que estudió María Teresa Iranzo, las cuales ponen de manifiesto la férrea administración y supervisión de las actividades cotidianas de un hospital señorial. Recordemos que entre las primeras disposiciones del duque de Híjar estaba el control de tahúres, picaros, alcahuetes y mujeres de mala fama (Iranzo, 1997: 105-124).

22 Diccionario de la lengua española (RAE). Un término siempre conectado al de hospitalero fue la del enfermero, profesión cuyas funciones estaban más encaminadas al cuidado sanitario del enfermo. Véase Suárez, 1997: 303-326. 
Problemas como éste no eran ajenos al arzobispo zaragozano García de Heredia. El 26 de marzo de 1404 la cancillería episcopal atendía los ruegos de Juan, hospitalero de la ciudad de Daroca. ${ }^{23}$ Dirigiéndose a los hombres buenos, jurados y al justicia de Daroca, el pontífice solicitaba un mayor control de algunos de estos grupos recién nombrados. Cerca de la puerta baja de la ciudad había sido construido y fundado recientemente un hospital para atender a pobres, peregrinos y mendicantes. ${ }^{24}$ Sin embargo, siguiendo las palabras del arzobispo García, tan caritativa obra pía se veía dificultada por la existencia de un prostíbulo. En este caso, la situación apartada, extramuros o cercana a las puertas de acceso de los hospitales coincidió con el desarrollo del lupanar y el trabajo de las meretrices. El problema ya no sería tanto la influencia sobre el hospitalero sino el propio mundo de marginación y delincuencia que rodeaba la prostitución. Ya el propio duque de Híjar advertía este aspecto en sus ordenanzas.

Por la situación del hospital, junto a la puerta inferior de la ciudad, podríamos pensar que se trataba del hospital de San Marcos, edificio que luego fue reutilizado como convento de los Trinitarios. No obstante, este hospital fue fundado en el siglo XIII. Creemos que la institución a la que se refiere el documento es el hospital de la Pasión. El nombre de su fundador coincide con el hospitalero, Juan de Román. Su ocupación, clérigo, también explica porqué la queja sobre el prostíbulo darocense se dirigió al arzobispo García de Heredia. ${ }^{25}$ Finalmente, la demanda del hospitalero también estaba motivada por la

23 Sobre la asistencial municipal en el concejo de Daroca consúltense el trabajo previamente citado: Rodrigo, 1995: 287-318. Nuevamente la documentación eclesiástica aporta también información: Marco, 1976-1977: 121.

24 La palabra «mendicante» no aparecía en los documentos que hemos visto hasta ahora. Claramente el término «pauper Christi» es mucho más amplio, mientras que «mendicante» recuerda a la persona que vive en la indigencia y que sobrevive gracias a la limosna. Es lógico encontrar este concepto en un contexto urbano y no en los pequeños hospitales rurales. Además de los pobres de Cristo, denominación más utilizada en las fuentes, la teología cristiana diferenciaba ya en el siglo XII entre «pauperes cum Petro» y «cum Lazaro». Los primeros representaban al clero que abogaba por una pobreza voluntaria, necesaria para un acercamiento a Dios, mientras que los segundos, estaban identificados propiamente con los pobres forzosos, laicos con miseria material. En conexión con estos últimos está también la denominación de los «pauperes verecundosi», los pobres vergonzantes: gentes de las clases altas y medias que vivían avergonzados por su nueva situación de penuria (Geremek, 1998: 32-34). «Pauperes Christi» estuvo en sus inicios relacionado al clero que renunciaba al lujo y seguía una vida sin la ostentación material. Pero en las fuentes que manejamos es sinónimo de persona laica, pobre y miserable.

25 La referencia nos la proporciona el bulario de Benedicto XIII. El pontífice concedió en 1398 un año y cuarenta días de indulgencias para aquellos que ayudaran al mantenimiento del hospital (Cuella, 2006: 362). 
perturbación y molestia que habría sufrido la limosna para la cruz de Cristo, la que arrastró durante la Pasión.

Además del control y la recepción del enfermo, los hospitaleros podían tener alguna responsabilidad en la administración económica del establecimiento. Si bien, en hospitales de mayor tamaño como el de Nuestra Señora de Gracia de Zaragoza o el de San Julián y Santa Lucía de Barbastro esa actividad quedaba en manos del bolsero, el mayordomo, el escribano de ración o el oidor de contos, en otros casos el propio hospitalero podía llevar perfectamente las cuentas. Así sucedía en el hospital de Santa María de Villaespesa y San Juan Bautista de Teruel, donde el hospitalero se encargaba de administrar los préstamos censales (Navarro, 2000: 573).

Nuevamente la fuente que estamos manejando nos ilustra este aspecto. El hospital zaragozano de Santa Marta había sido fundado en 1315 por el médico Guillermo Fuerte. Se encontraba en la parroquia de San Salvador, es decir, cerca de la catedral de la ciudad. Desde sus inicios daba alojamiento a doce pobres o peregrinos que se dirigieran a Santiago de Compostela (Falcón, 1980: 190). ${ }^{26}$ Al igual que el hospitalero de Daroca, el hospitalero de Santa Marta se vio obligado a acudir ante el arzobispo García de Heredia en 1400. $\mathrm{Su}$ problema radicaba en la falta de liquidez para mantener el hospital. Ese dinero faltante no era consecuencia de su mala administración o de su derroche, sino de la pasividad. Ya en 1390 los administradores de Santa Marta, el arzobispo y los vicarios generales habían establecido una serie de réditos y de depósitos beneficiosos para el hospital. Parece ser que diez años después el cobro de esas cuentas era indebido. García de Heredia exhortaba a sus oficiales para que pusieran solución a aquel problema y para que revisaran la documentación conservada al respecto. Más allá del caso de Santa Marta, el texto evidencia la división de las tareas económicas del inmueble. Los administradores y oficiales de la curia fueron quienes cerraron aquellos negocios, tributos o réditos, mientras que el hospitalero era quien se encargaba de los gastos cotidianos. ${ }^{27}$

26 Ana del Campo describe de la siguiente manera la figura de Santa Marta: «No debe extrañarnos en absoluto la elección de Marta como patrona de un hospital, pues ella representa a la mujer servicial y trabajadora que sirve a los demás en silencio. [...] Se le representa muchas veces con un perol de comida y siempre con un manojo de llaves en la cintura, como si ejerciese de perfecta ama de llaves» (Del Campo, 2001-2002: 109).

27 ADZ, RAC, t. III (1400-1401), ff. 51v-52v. 


\section{Limosnas por indulgencias}

Entre los registros de actos comunes del Archivo Diocesano de Zaragoza encontramos, ya en tiempos de los primeros arzobispos, una serie de licencias concedidas a iglesias, ermitas y hospitales para pedir limosnas. Las cartas que contenían el permiso para recaudar limosnas por diversos lugares de la diócesis cesaraugustana recibieron primero el nombre de littera queste, después littera indulgencia y por último, durante el pontificado de García Fernández de Heredia, privilegium. Desde el paso de obispado a arzobispado los prelados zaragozanos concedieron estos privilegios a hospitales, tanto de dentro como de fuera de su diócesis. A los de dentro de la diócesis, las menciones se concentran en torno a las ciudades de Zaragoza, Teruel y Daroca. Fuera de la diócesis, pero todavía en el reino de Aragón, el hospital de leprosos de Ariza o los hospitales para peregrinos de Tiermas y Santa Cristina de Somport fueron algunas de las instituciones que se beneficiaron de tales concesiones. Y por último, más allá de los límites eclesiásticos y de las fronteras políticas aragonesas fueron numerosos los hospitales urbanos y rurales, según que casos en conexión con un monasterio, quienes disfrutaron esta actividad. Dentro de la Península Ibérica encontramos monasterios y grandes hospitales como la Santa Cruz de Barcelona, Santa María de Monserrat de Vic, Santa María de Roncesvalles o Santo Domingo de Silos en Burgos. Entre los hospitales mencionados en territorio castellano parece que existió una predilección por las leproserías. En este sentido, los hospitales de San Lázaro de Quesada, Úbeda, Valladolid y Palencia también aparecen nombrados en la documentación. En territorio francés los privilegios llegaron hasta Santa María de Podio de Amiens y Santa Quiteria de Aire, así como al Santo Espíritu de Roma (Pueyo, 2000: 683-708). ${ }^{28}$

Gracias a esta documentación, personas responsables de estos hospitales, al igual que iglesias y ermitas, podían recorrer la diócesis zaragozana recaudando limosnas, las cuales solían invertirse en reparaciones y mantenimiento. Para una mayor atracción de los parroquianos del lugar, las licencias concedidas por el arzobispo o sus vicarios se acompañaban de indulgencias. Una indulgencia era, en palabras de Daniel Baloup, «un privilegio de origen pontificio o episcopal que garantiza al beneficiario una reducción parcial o total de penitencia.» Si bien el discurso sobre la indulgencia estaba ya presente en el

28 Véase además el anexo número 1, donde se recogen las licencias para pedir limosnas por la diócesis zaragozana, otorgadas a instituciones que no pertenecían a dicha circunscripción eclesiástica. 
siglo XI, no fue hasta el siglo XIII cuando se hicieron más comunes, multiplicándose a finales de la Edad Media. La disminución de la pena podía llegar motivada por una actividad devocional, sin embargo, «lo que permite ganar el preciado privilegio es la limosna a un santuario, a un hospital o a una orden religiosa.» (Baloup, 2003-2004: 62). ${ }^{29}$

Debido a la repetición de las fórmulas diplomáticas en este tipo de documentos, seleccionamos a modo ilustrativo la licencia concedida para la iglesia y hospital de San Jorge de Teruel. La licencia la emitió Juan Boecio, vicario, en nombre del arzobispo García de Heredia. El documento expedido pasaría a manos de los administradores y cuestores de dicho hospital, aunque el texto evocaba al clero de toda la diócesis cesaraugustana, quienes debían permitir la recogida de limosna en sus respectivas parroquias. La concesión coincide con la reciente construcción del hospital de San Jorge, el mártir soldado, para atender a pobres y peregrinos que pasaban por la ciudad. Se encontraba a las afueras de la ciudad — «in suburbio sive ravali dicte civitatis»-, como ocurría con otros tantos establecimientos similares. De esta forma el tránsito de peregrinos se mantendría fuera del circuito urbano, así como los problemas que pudieran generarse en contextos de marginación y pobreza. Anteriormente ya existió allí una institución con funciones semejantes, el hospicio de Benedicto Mata. ${ }^{30}$ La licencia para el hospital de San Jorge de Teruel permitía a los cuestores de la institución que recorrieran la extensa diócesis de Zaragoza. A su llegada a cada localidad el párroco convocaba a sus feligreses a toque de campana. Reunida la comunidad se explicaban las necesidades de las diferentes instituciones que fueron beneficiarias de estas licencias, no sólo hospitales, así como los beneficios espirituales que obtenía el creyente al dar su limosna. En este caso, las indulgencias por el hospital de San Jorge comportaban triginta dies de indulgencias (Pueyo, 2001: 315-352).

La propia ciudad de Teruel contó con establecimientos hospitalarios desde la conquista cristiana en la segunda mitad del siglo XII. El de San Redentor y

29 La culminación del ejercicio de la indulgencia puede verse como una evolución de la economía de la salvación, de la que ya hablaba Bronislaw Geremek en su capítulo: «El medievo: ¿son necesarios los pobres?» (Geremek, 1986). El pobre en la Edad Media tiene una función social que es la de salvar a través de la limosna y la caridad al resto de la población. En esa ecuación, la Iglesia juega un papel fundamental ya que se convierte en mediadora para la redención de sus feligreses. En este caso, la fórmula limosna-pobre-salvación se transforma en limosna-hospital-salvación, siendo las instituciones eclesiásticas y asistenciales las receptoras de las donaciones.

30 ADZ, RAC, t. VI (1407-1408), f. 3r-v. 
el de San Marcos fueron de los primeros, siendo su principal actuación la redención de los cautivos. Los siglos sucesivos llegaron con nuevas fundaciones como el hospital de San Sebastián, el de San Juan Bautista, el de San Lázaro o el de San Gil, este último promovido por la corporación de los pellejeros (Gargallo, 1996: 199-202). Más allá de una simple enumeración de los hospitales de la ciudad, destaca un fenómeno en el Teruel del siglo XV y XVI: la concentración hospitalaria dual.

En las ciudades de la Corona de Aragón del Cuatrocientos, y en los primeros momentos de la centuria siguiente, el fenómeno hospitalario se sirvió de nuevos métodos asistenciales. Nacieron entonces los hospitales generales urbanos. Para ello se requería una concentración de los esfuerzos de las instituciones, dando cada vez más importancia y recursos a estos nuevos hospitales. Las estrategias de concentración fueron principalmente tres. La primera la ejemplifican los hospitales de la Santa Cruz de Barcelona o el de San Nicolás de Bari, este último ya comentado. Nueve pequeños hospitales, en la ciudad condal, y cuatro, en Alcañiz, unieron sus recursos y rentas para crear una institución de mayor capacidad. En Zaragoza se optó por fundar un hospital nuevo, el de Nuestra Señora de Gracia, y dejar que los pequeños hospitales fueran desapareciendo o readaptándose. Ésta es la segunda solución: fundar un nuevo establecimiento. Y la tercera dirección fue la concentración dual. Se dio en ciudades de menor tamaño y como su nombre indica, supuso la suma de dos establecimientos. El resultado de estos hospitales se distingue rápidamente si nos fijamos en su doble advocación: el de San Juan Bautista y el Espíritu Santo en Jaca, San Julián y Santa Lucía en Barbastro y Santiago y Santa María en Daroca.

Uniendo la documentación de los registros de actos comunes con otra de procedencia variada podemos ofrecer algunos trazos de este fenómeno en la ciudad de Teruel. Del hospital de San Juan Bautista y Santa María de Villaespesa ya hemos hablado, pero el listado sigue con dos casos más. El primero tiene que ver con el previamente citado hospital de San Jorge. Al menos en 1514 su titularidad ya estaba compartida, ya que Luis Camañas era el hospitalero de San Jorge y Santa Bárbara. ${ }^{31}$ Lo mismo sucedió con Jerónimo Castellot en 1529, pero en el hospital de San Julián y San Bartolomé. ${ }^{32}$

Por último, y cerrando este punto, retornamos nuevamente a las licencias e indulgencias para observar lo generalizado de este fenómeno. Ya hemos ha- 
blado de los hospitales, iglesias y monasterios que siendo de fuera de la diócesis podían pedir limosnas en los dominios de García de Heredia. Uno de ellos fue el hospital de San Antonio, de la diócesis francesa de Amiens. Su importancia fue tal que no sólo desde la curia zaragozana se concedieron privilegios de este tipo, también desde la corte papal. En 1411 Benedicto XIII ordenó al obispo de Segorbe, al abad del monasterio valenciano de San Bernardo y al oficial de Tortosa que facilitaran la entrega de legados y limosnas para el hospital de pobres del monasterio de San Antonio (Cuella, 2011: 51). Como vemos, los recursos a favor de estos importantes hospitales, muchos de ellos también monasterios, llegaban más allá de las fronteras políticas y eclesiásticas.

\section{A modo de conclusión}

En las postrimerías de la Edad Media la Iglesia ejerció todavía un protagonismo muy notable. Pese al proceso de laicización que permitió que nuevos actores sociales participaran en la gestión de los hospitales, los prelados seguían manteniendo su influencia sobre la comunidad de fieles y las autoridades municipales. Tanto los hospitales urbanos y parroquiales como las pequeñas empresas rurales fueron objeto de atención constante. Y aunque en estas líneas no hayamos profundizado al respecto, tampoco podemos olvidar la función espiritual de los hospitales y del cuerpo eclesiástico en ellos presente. Esta labor ha quedado relegada por la historiografía frente a la asistencia corporal y los cuidados que proporcionaban los hospitales.

Los múltiples esfuerzos realizados por la Iglesia católica en el ámbito de la caridad suponen para el historiador un vasto campo de estudio. Su papel de mediadora con la divinidad en las épocas medieval y moderna la coloca como intermediaria de la sociedad. Profundizar en ella significa abordar la colectividad con múltiples perspectivas, planteándonos el papel de las élites y los marginados. Y entre el amplio espacio entre unos y otros, el que separaba al arzobispo de Zaragoza y un peregrino alojado en Muniesa, se encontraban las instituciones hospitalarias. En ellas la actuación de los prelados se complementó con aquellas acciones individuales de sus subordinados.

En segundo lugar, destaca el complejo sistema de entramados institucionales. Únicamente con los registros de actos comunes del Archivo Diocesano de Zaragoza se distinguen varios planos de la red hospitalaria. Con una escala 
menor es posible apreciar el mundo rural y la proliferación de estos establecimientos a partir del siglo XIV. Por un lado, se observa cómo durante el siglo $\mathrm{XV}$ fue cuando la mayor parte de ellos se convirtieron en empresas públicas bajo la administración municipal. Y por otro, son los caminos secundarios devocionales y de peregrinación la temática de estudio que se perfila. En una escala mayor, a nivel peninsular y europeo, se observan fenómenos igual de importantes como el tráfico de indulgencias y limosnas. De todo ello se extrae que la red institucional es global y que no se limita ni a las fronteras físicas, políticas o eclesiásticas.

Por último, esta aproximación a la documentación eclesiástica evidencia las todavía posibilidades de estudio que ofrecen estas fuentes. El vaciado sistemático de sus fondos y la unión con otras tipologías documentales nos permitirá pasar de lo anecdótico y circunstancial a la reconstrucción de procesos de mayor amplitud. 


\section{Anexo $\mathrm{N}^{\mathrm{o}} 1$ :}

\section{Noticias de hospitales de fuera de la diócesis de Zaragoza ${ }^{33}$}

\begin{tabular}{|c|c|c|c|c|}
\hline & Hospital & Lugar & Diócesis & Ref. documental (ADZ) \\
\hline 1 & Santa María de Podio & \multicolumn{2}{|c|}{ Amiens } & $\begin{array}{l}\text { RAC. 1387-1397, ff. 5v-6v; } \\
\text { RAC. 1400-1401, ff. 579v- } \\
\text { 580r; RAC. 1405-1406, ff. } \\
\text { 131r-v; RAC. 1407-1408, ff. } \\
\text { 199v-200r; RAC. 1409-1411, } \\
\text { ff. 123r y 280r. }\end{array}$ \\
\hline 2 & San Marcial & \multicolumn{2}{|c|}{ Limoges } & $\begin{array}{l}\text { RAC. 1387-1397, ff. 3v-4v; } \\
\text { RAC. 1400-1401, ff. 192r- } \\
\text { 193r; RAC. 1405-1406, ff. } \\
\text { 240r-241r; RAC. 1407-1408, } \\
\text { ff. 300r-301r. }\end{array}$ \\
\hline 3 & San Antonio & \multicolumn{2}{|c|}{ Vienne } & $\begin{array}{l}\text { RAC. } 1387-1397, \text { ff. } 40 v-43 v \text {; } \\
\text { RAC. } 1402-1404, \text { ff. } 144 v- \\
\text { 146v; RAC. 1405-1406, ff. } \\
\text { 128r-130r. }\end{array}$ \\
\hline 4 & Santa Quiteria & \multicolumn{2}{|c|}{ Aire } & $\begin{array}{l}\text { RAC. 1387-1397, ff. 17r-18r; } \\
\text { RAC. 1400-1401, ff. 5v-6r; } \\
\text { RAC. 1402-1404, ff. 238v- } \\
\text { 239v y 370r-v; RAC. 1405- } \\
\text { 1406, ff. 354v-355r; RAC. } \\
\text { 1407-1408, ff. 280v-281r; } \\
\text { RAC. 1409-1411, ff. 256v. }\end{array}$ \\
\hline 5 & \multicolumn{2}{|c|}{ Santa María de Roncesvalles } & Pamplona & $\begin{array}{l}\text { RAC. 1346-1385, ff. 64v- } \\
\text { 66v; RAC. 1387-1397, ff. } \\
\text { 61r-63v; RAC. 1402-1404, ff. } \\
\text { 450v-452r; RAC. 1409-1411, } \\
\text { ff. 215v-216v. }\end{array}$ \\
\hline 6 & \multicolumn{2}{|c|}{ Santa Cristina de Somport } & Huesca & $\begin{array}{l}\text { RAC. 1400-1401, ff. 506r-v; } \\
\text { RAC. 1405-1406, ff. 389r. }\end{array}$ \\
\hline 7 & \multicolumn{2}{|l|}{ Tiermas } & Jaca & $\begin{array}{l}\text { RAC. } 1346-1385 \text {, ff. } 27 \mathrm{v}-28 \mathrm{r} \\
\text { y } 362 \mathrm{v}-363 \mathrm{r} .\end{array}$ \\
\hline
\end{tabular}

33 Materiales elaborados a partir de las siguientes obras: Pueyo, 2000: 683-708; Lasarte, 2002 (inédito); Lasarte, 2003 (inédito); Pueyo, 2011: 315-352. En general las referencias son licencias para pedir limosnas por la diócesis de Zaragoza. 
Aproximación a los hospitales a través de los registros de actos comunes de la Archidiócesis...

\begin{tabular}{|c|c|c|c|c|}
\hline 8 & Santo Domi & ilos & Burgos & $\begin{array}{l}\text { RAC. 1387-1397, ff. 45v-46v; } \\
\text { RAC. 1400-1401, ff. 581v- } \\
\text { 582r; RAC. 1402-1404, ff. } \\
\text { 323v-324r; RAC. 1405-1406, }\end{array}$ \\
\hline 9 & San Lázaro & \multicolumn{2}{|c|}{ Palencia } & RAC. 1409-1411, ff. 391r-v. \\
\hline 10 & San Lázaro & \multicolumn{2}{|c|}{ Valladolid } & $\begin{array}{l}\text { RAC. } 1407-1408 \text {, f. 273v; } \\
\text { RAC. 1409-1411, ff. 259r-v. }\end{array}$ \\
\hline 11 & San Lázaro & Ariza & Sigüenza & $\begin{array}{l}\text { RAC. } 1400-1401, \text { ff. } 1 r-2 r ; \\
\text { RAC. } 1402-1404, \text { ff. } 227 r- \\
\text { 228v; RAC. 1407-1408, ff. } \\
\text { 87v-88r. }\end{array}$ \\
\hline 12 & Santa Bárbara & \multicolumn{2}{|c|}{ Gerona } & $\begin{array}{l}\text { RAC. } 1387-1397, \text { ff. } 53 \mathrm{v}-54 \mathrm{v} \text {; } \\
\text { RAC. } 1405-1406, \text { f. } 130 \mathrm{v} .\end{array}$ \\
\hline 13 & $\begin{array}{l}\text { Santa María } \\
\text { de Monserrat }\end{array}$ & \multicolumn{2}{|c|}{ Vic } & RAC. 1387-1397, ff. 18r-19r. \\
\hline 14 & Santa Cruz & \multicolumn{2}{|c|}{ Barcelona } & $\begin{array}{l}\text { RAC. 1405-1406, ff. 151r- } \\
\text { 152r; RAC. 1409-1411, ff. } \\
\text { 230r-v. }\end{array}$ \\
\hline 15 & San Lázaro & Úbeda & Baeza & $\begin{array}{l}\text { RAC. } 1407-1408, \text { ff. } 224 r-v ; \\
\text { RAC. } 1409-1411, \text { ff. } 59 v \text { y } \\
\text { 273v. }\end{array}$ \\
\hline 16 & San Lázaro & Quesada & Baeza & $\begin{array}{l}\text { RAC. } 1407-1408, \text { ff. } 224 \mathrm{r}-\mathrm{v} \text {; } \\
\text { RAC. } 1409-1411, \text { ff. } 59 \mathrm{v} y \\
273 \mathrm{v} .\end{array}$ \\
\hline 17 & Santo Espíritu & \multicolumn{2}{|c|}{ Roma } & $\begin{array}{l}\text { RAC. 1346-1385, ff. 43v- } \\
\text { 45v; RAC. 1387-1397, ff. } \\
\text { 46v-48v; RAC. 1400-1401, } \\
\text { ff. 590r-592r; RAC. 1405- } \\
\text { 1406, ff. 97v-99v. }\end{array}$ \\
\hline
\end{tabular}




\title{
Anexo $n^{\circ} 2$ : Transcripción documental
}

\author{
1.
}

8, marzo, 1400. Zaragoza.

El arzobispo García de Heredia ordena a los administradores del hospital de Santa Marta y a los otros cargos de la curia arzobispal que ejecuten los réditos del hospital para que Juan Burreti, hospitalero del establecimiento pueda usarlos en la reparación y mantenimiento del establecimiento.

ADZ, RAC, t. III (1400-1401), ff. 51v-52v.

\section{/f. 51v/ Per Johanem Burreti}

Garsias miseracione divina archiepiscopus Cesarauguste. Dilectis in Christo officiali nostro Cesarauguste vel eius locatenentibus ceterisque universis et singulis comissariis ac rectoribus sive administratoribus hospitalis Sancte Marte, constructe in parrochia Sancti Salvatoris sedem nostre Cesarauguste, ac receptoribus et depositariis tributorum redditum obvencionum et jurium eiusdem hospitalis ab anno a Nativitate Domini $\mathrm{M}^{\circ} \mathrm{CCC}^{\circ} \mathrm{XC}^{\circ}$ per nos seu nostros vicarios generales deputatis et ordinatis usque ad festum Omnium Sanctorum proxime lapsum et signanter venerabilis Poncio de Bruno, decretorum doctori, precentori Vicensis olim, officiali nostro Cesarauguste et quibusuis locatenentibus suis Johanni de Lines, rectori de Villafranca, seu eius procuratori ac heredibus et detentoribus bonorum, Bernardi de Sames, quondam rectoris de Palomar nostre diocesis, venerabilis Petro Bolea, canonico ecclesie nostre predicte, Petro Gallici, nunc vicario Sancti Philippi Caesaraugustis, et Petro Egidii, marques presbitero vicario cappelle sedis nostre jam dicte necnon quibusvis notariis et scriptoribus curie /f. 52r/ dicti officialatus nostri Cesarauguste preteritis et qui nunc sunt et aliis quibuscumque ad quem vel quod spectet et presentes pervenerint et singulis eorum, salutem in Domino.

Comperens coram nobis dilectus in Christo Johannes Burreti, presbiter porcionarius dicte sedis et hospitalarius hospitalis, jamdicti exposuit reverenter quod vos seu aliqui vestrum tenetis ac tenent per viam depositi seu alia plures et diversas peccuniarum quantitates de tributis redditibus et juribus dicti hospitalis a dicto anno $\mathrm{XC}^{\circ}$ citra habitis sive depositis et receptis que in reparaçione augmento et utilitate dicti hospitalis sunt convercende. Quare supplicato nobis super hoc de condescendi justitie remedio provideri, vos et vestrum singulos harum tenore monemus, semel, secundo, tercio et peremtorie vobisque nichilominus invingentes quatenus infra XV dies a die qua presentes receperitis seu vobis notifficatis et intimate fuerunt inantea continue et inmediate sequentes quorum quinque pro primo, quinque pro secundo et reliquos quinque dies pro tercio et peremptoria terminis trinaque et canonica monitione vobis omnibus / et singulis $\backslash$ assignamus tradatis et deliberetis cum effectum prefato Johanni Burreti, hospitalario, quecumque tributa redditus obvenciones et jura dicti hospitalis penes vos et singulos vestrum per viam depositi seu alia a dicto anno $\mathrm{XC}^{\circ}$ citra et usque ad dictum festum Omnium Sanctorum proxime lapsum exentia recuperando tamen ab eodem albarana, sive apocas, de soluto vosque etiam notari et scriptores predicti tradatis dicto hospitalario previa satisfactione con digna coppiam signatam et in judicio fidem ferentem de quibusuis depositis seu comandis 
dictorum tributorum reddituum et jurium quorumcumque hospitalis jam dicti per vos et vestrum singulos testifficatis seu in libris dicte curie officialis nostri aut aliis scriptis et annotatis cum quibus ea valeat hospitalarius jamdictus, petere, recuperare, exigere /et $\$ habere vel cum dicto hospitalario super predictis vos interim amicabiliter componatis, aut ultima die dicti termini non feriata compereatis coram nobis seu deputando a nobis Cesarauguste proposituri in judicio causas justas siquas habetis vel habere creditis, quibus non teneamini ad predicta, alio quod lapso dicto termino XV dierum monitione huiusmodi canonica precedentis ac presentacione et notifficacione inde nobis facta quam vobis et aliis quibuscumque pro ut expediens fuerit per universos et singulos presbiteros curatos et non curatos civitatis Cesarauguste in virtute sancte hobedientie fieri volumus et mandamus in vos et vestrum singulos nisi feceritis que mandamus nunc pro tunc et tunc pro nunc excomunicationis sententiam ferimus in hiis scriptis mandantes eisdem prebiteris quod huiusmodi literam dicto hospitalario /f. 52v/ reddant cum relacione horum que fecerint in predictis coppia inde vobis tradita si eam pecieritis vestris tamen sumptibus et expensis providentes et ordinantes in super quod dictus Johannes Burreti, hospitalarius, convertat in utilitate reparacione et augmento dicti hospitalis ad congnicionem venerabili et religiosi viri dompni Dominici Ram, legum doctoris, canonici et caritatarii ac officialis nostri Cesarauguste quidquid receperit expredictis. Datum Cesarauguste die VIII ${ }^{\mathrm{a}}$ marcii anno a Nativitate Domini $\mathrm{M}^{\circ} \mathrm{CCCC}^{\circ}$. Vidit Petrus Vilana, vicarius.

\section{2.}

2, octubre, 1400. Teruel.

El arzobispo García Fernández de Heredia concede cuarenta días de indulgencias a quienes ayuden con sus limosnas a la iglesia y hospital de San Fabián y San Sebastián de Teruel.

ADZ, RAC, t. III (1400-1401), f. 169r.

/f. 169r/ Privilegium Sancti Sebastiani Turolii.

Garsias etc. Dilectis in Christo universis et singulis prioribus, archipresbiteris, plebanis, rectoribus et vicariis ceterisque presbiteris curatis per civitatem et diocesis nostram Cesarauguste constitutis ad quem vel quos presentes pervenerint, salutem in Domino, et bonis semper operibus abundare. Tanto vos et alios Christi fidelis ad pietatis et caritatis opera libencius invitamus quanto ad ea exercenda, vos et eos invenire credimus prompciores. Cum itaque Petrus Valero, procurator et administrator ecclesie et hospitalis Sanctorum Sebastani et Fabiani civitatis Turolii, nostre diocesis, lator presenciam ad reparacionem dicte ecclesie quod evidenter minatur ruinam, et in qua dominus nostrum Ihesus Christus nuncis dictorum Sanctorum Martirum multa et diversa miracula operatur et alias necessitates hospitalis eiusdem indegeat Christi fidelium helemosinus /et sucursu. Idcirco vobis in virtute sancte hobedientie dicimus et mandamus, quatenus cum dictus Petrus ad vos seu ecclesias vestras declinaverit Christi fidelium helemosinas petiturus, $\backslash$ petiturus [sic.] presentibus comunitus ipsum benigne recipiatis et caritative tractetis ac permictatis in vestris ecclesiis et parrochiis helemosinas petere et congregare. Eumque plebibus vobis comissis presentetis plebes easdem ad benefaciendum eidem salubribus, monitis et exortacionibus inducendo. Sperantes ab illo premium qui in centuplum remunerat omne bonum. Nos enim de omnipotentis dominum Dei misericordia beatorum quoque Petri et Pauli apostolorum eius ac Valerii anthistitis et patroni nostri meritis confidentes omnibus et singulis Christi fidelibus vere penitentibus et confessis qui ad reparacionem et necessitatem dicte ecclesie et hospitalis eiusdem manus suas porrexerint 
quomodolizet adiutrices XL dies de iniunctis eis legittime penitenciis per graciam Sancti Spiritus misericorditer in Domino relaxamus. Presentibus post bienium minime valituris. Datum Turolii, die secunda octobre anno $\mathrm{CCCC}^{\circ}$. Vid Pere Vilana, vicaris.

3.

26, marzo, 1404. Zaragoza.

El arzobispo García Fernández de Heredia ruega a los hombres buenos de la ciudad de Daroca que intervengan ante las perturbaciones que sufre el nuevo hospital y su hospitalero, debido a su situación próxima con un prostíbulo.

ADZ, RAC, t. IV (1402-1404), ff. 385v-386r.

/f. 385v/ Pro hospitalario Daroce.

Garsias et etc., honorabilis et discretis viris, justicie, juratis et probiis hominibus civitatis Daroce, nostre diocesis, salutem in Domino. Et proactum ad vestri beneplacita voluntatem in nostra presenciam constitutus dilectus in Christo Johanes, nostrum hospitalarius novi hospitalis constructi et fundati prope portam inferiorem dicte civitatis, proposuit reverenter quod ipse pro Dei servicio volens temporalia in specialibus conmutare mediantibus helemosinis Christi fidelium hedifficavit dictum hospitale quod erint certo precio cum certis aliis domibus circumadiacentibus et dicto hospitali neccesaris ut pauperes Christi, peregrini et ceteri mendicantes ibi amore Dei valeant hospitari de qua quidem empcione sive empcionibus inde factis de solucione pretii constare de publiciis instrumentis quorum vigore et alter ipse ut hospitalarius predictus et dictum hospitale et ut asservit possesionem pacica et quieta ipsarum domorum et eo sit possidete vos seu aliqui vestrum ipsum hospitalarium supradictam sua possesione de facto absque alicuius cause cognicione interim ut asseritur indebite perturbare. Mandando sibi se eius locutenenti in dicto hospitali per aliquas ex dictis domibus hospitalis predicti dimittat pro lupanari ubi meretrices valeant comorari de quo si ita sit vehementer et non merito cogimur admirari nam hospitalia et loca pia ordinata ad Dei servicium et usarum Christi pauperum non debunt tam illicitis, orrendis et nefandissimis usibus assignavi, unde dictus hospitalarius turbatus in suo santo proposito ad nos recurrens firmavit de directo super dicta sua possesione in posse nostro et de stando viri vobis et quibusuis aliis de eo querimoniam herentibus quovisi modo et supplicavit per nos in predictis de condescenti justicie remedio providi. Nos enim attendentes quod nostro pastorali incubite officio ecclesiastico hospitalia et alia sacra et pia loca in suis vestribus deffendere et tueri prudentiam vestram de qua talia procedere inullatum oppinamur, rogamus, monemus et in Domino exortamur vobisque in ecclesia inhibemus quatenus dictum hospitalarium supradictam possesione et administracione dicti hospitalis et domorum eiusdem ipsius hospitalis, et pauperum Christi ibi convenientium usibus et necesitatibus /f. 386r/ assignatarum et deputatarum quas ut preffertur erint et possidet vistis, titulis cum helemosinis cruciffixi nullatis, inquietetis, molestetis seu perturbaretis ymo a predictis desistendo sinatis ipsum et Christi pauperes sua publica possesione gaudere in hoc enim servietis Deo. Et complacebitis nobis multum si contratium vero feceritis directe vel indirecte publice vel occulte quod de vobis ut preffertur nullatum speramus serenimus licet invite vestre tamen nostre compulsi in et super predictis ac incontradictores procedere vestris remediis et aliis omnibus quibus decet.

Tamen si aliquas, vistas cartas habetis quibus non teneamini ad predictam eas per vestris ydoneum procuratorem coram nobis seu vicario nostro generali. Cesarauguste in judicio propo- 
Aproximación a los hospitales a través de los registros de actos comunes de la Archidiócesis...

natis infra duodecim dies videlicet ultima die ipsius termini non feriata quem terminum uno e dicto pro tribus et pemptis assignamus ut precatur laboribus et expensis interim vero super predictis vel providenciale, innovetis seu innovari faciatis, offerentes ad omnia que vestro contenerat beneplacitum et honorem. Datum Cesarauguste, die XXVI ${ }^{\mathrm{a}}$ madii anno a Nativitate Domino $\mathrm{M}^{\circ} \mathrm{CCCC}^{\circ}$ quarto.

3, abril, 1405. Zaragoza.

El arzobispo García Fernández de Heredia aprueba la construcción de un nuevo hospital en Fuendetodos con motivo de la mala administración que había llevado el hospital viejo a la ruina.

ADZ, RAC, t. V (1405-1406), f. 55r-v.

/f. 55r/ Per hospitale de Fuent de Todos.

Garsias et etc., dilecto in Christo vicario, et juratis loci de Fuent de Todos, nostre diocesis, salute in Domino. Cum sicut pro parte vestra fuit proponitum humiliter coram nobis in dicto /f. $55 \mathrm{v} /$ sit unum hospitale anticum quos vicio fundamenti vel propter malam administracionem corruit sucessibus ruinosis et belicis emere alius hospicium pro hospitali in quo Christi pauperes valeant. Ospitari suplicaveritisque nobis ut vendendi domos ruinosas dicti hospitalis antiqui et precium earum in emptione edifficacione et aliis necesitatitus dicti novi hospitalis potiendi et convertendi nobis pro Dei servicio licenciam concedem dignaremur nos piis votis vestris annuentes ac volentes bonis. Operibus dare locum ut dictum antiqum hospitalis vendere in precium inde habendum in emptione hedifficacione et aliis necesitatibus dicti novi hospitalis convetere libere valeatis vobis si est ita et non aliam licenciam et facultatem presentibus impertimum. Datum Cesarauguste, die III ${ }^{\mathrm{a}}$ aprilis anno a Nativitate Domini Millesimo quadringentesimo quinto. Garcia archiespiscopus.

20, agosto, 1405. Zaragoza.

Los vicarios generales conceden treinta días de indulgencias a quienes ayuden con sus limosnas a la iglesia y hospital de Santa María del Pilar de Zaragoza.

ADZ, RAC, t. V (1405-1406), f. 126v.

/f. 126v/ Privilegium beate Marie de Pilari Cesarauguste

Vicarii generales et etc. universis Christi fidelibus per civitatem et diocesis Cesarauguste constitutis, ad quos presentes pervenerit, salutem in Domino et bonis semper operibus abundare. Tanto vos ad pietatis opera libencius invitamus quanto ad ea exercenda vos invenire credimus promptiores. Cum igitur ecclesia beatissime Virginis Marie del Pilar, civitatis Cesarauguste, in qua dominus nostrum Ihesus Christus ex assuete pietatis misericordia et intuitu beatissime Virginis Marie eius genitricis cuius altare ibidem edifficatum et constructum existit multa et inmensa miracula operatur indigeat auxilio et sucursu nostrorum et aliorum Christi fidelium propter multa et plurima omnia dicte ecclesie et cuiusdam hospitalis ipsius ecclesie suportanda. Idcirco universitatem et devocionem vestram in Domino exortamur et etiam monemus in remissionem vestrorum peccaminum, quatenus de bonis vestris vel adeo collatis eidem ecclesie et 
hospitali, pias helemosinas et grata caritatis subsidia per latorem presenciam nostram transmittatis ut per subvencionem vestram el aliorum Christi fidelium dicte ecclesie et hospitali predicto in necessitatibus succurratur, vosque per hec et alia bona que Domino inspirantis feceritis ad eterna possitis gaudia feliciter pervenire. Vobis auctoritate prioribus, archipresbiteris, plebanis, rectoribus et vicariis et aliis clericis curatis et non curatis et vestrum locatenentibus civitatis et diocesis predicte in virtutis sancte obedientie dicimus et mandamus, quatenus cum nuncium, seu nuncios, preffate ecclesie et hospitalis latores presencium ad ecclesias et loca vestram declinare contigerit pro petendis helemosinis ad oppus ipsorum ecclesie et hospitalis ipsos benigne recippiatis et populis vobis comissis libere presentetis neccesitatem ipsius ecclesie et hospitalis exponatis eisdem vel per ipsos nuncios exponi libere permittatis populos ad benefaciendum eisdem ecclesie et hospitali monitis, et exortacionibus inducendo. Volumus autem quod presens questa pro nulla alia retardetur, vel etiam impediatur excepta ecclesie Cesaraugustane quam hinc et omnibus aliis volumus antefferi. Concedentes in super dicto nuncio ut ad maiorem devocionem populi exitandan crucem secum defferre valeant licite et honeste. Nos enim de omnipotentis Domini nostri Ihesu Christi misericordia beatorum quoque Petri et Pauli apostolorum eius auctoritate et Sancti Valerii, confessoris et patroni ecclesie Cesaraugustane, meritis confidentes omnibus et singulis Christi fidelibus vere penitentibus et confessis qui dicto nuncio presentibus comito pro oppere et neccesitate dicte ecclesie et hospitalis eiusdem manus suas porrexerint quomodolizet adiutrices triginta dies de iniunctis sibi legittime penitenciis per graciam Sancti Spiritus misericorditer in Domino relaxamus. Presentibus post biennium inantea computandis minime valituris. Datum Cesarauguste die $\mathrm{XX}^{\mathrm{a}}$ mensis augusti anno a Nativitate Domini $\mathrm{M}^{\circ} \mathrm{CCCC}^{\circ}$ quinto. Vidit Petrus Ramus, vicarius.

Item fuerunt expedita alia duo con similia privilegia ex parte domini archiepiscopi. Data Cesaraguste, die VI ${ }^{\mathrm{a}}$ octobre anno predicto.

6.

28, diciembre, 1406. Teruel.

Juan Boecio, vicario de Vic y vicario general, concede treinta días de indulgencias a quienes ayuden con sus limosnas al hospital de San Jorge de Teruel, recientemente edificado.

ADZ, RAC, t. VI (1407-1408), f. 3r-v.

/f. 3r/ Privilegium hospitalis Sancti Georgii Turolii.

Johannes Boeci et etc. Dilectis in Christo universis et singulis prioribus, archipresbiteris, plebanis, rectoribus et vicariis ceterisque presbiteris curatis per Cesarauguste diocesis constitutis, ad quem /vel quos presentes pervenerintl, salutem in Domino et bonis semper operibus habundare. Cum inter alia bona misericordie opera notabiliter volut Deo placida comendentur et in civitate Turolii, Cesarauguste diocesis, videlicet in suburbio sive ravali dicte civitatis in hospicio Benedicti Matha, vulgariter nominato, sit hedificatum, ordinatum et constructum noviter unum hospitale sub invocatione et devocione beati Georgii, militis et martiris, in quo Christi pauperes et peregrini ad illud declinantes recolliguntur et hospitantur, et per hospitalarium dicti hospitalis in suis necessetatibus sincera in Domino caritate tractaretis et misericordie opera laudabiliter adimplentur, et non possit absque Christi fidelium helemosinis sustentari. Idcirco auctoritate prefati domini nostri archiepiscopi, vobis in virtute sancte hobedientie dicimus et mandamus, quatenus cum hospi- /f. $3 \mathrm{v} /$ talarius sive procurator aut nuncius dicti hospitalis ad vos seu ecclesias vestras declinaverit ad opus et necessitatem dicti hospitalis Christi 
Aproximación a los hospitales a través de los registros de actos comunes de la Archidiócesis...

fidelium helemosinas petituris ipsum benigne recipiatis et caritative tractetis vobisque comissis plebibus presentetis plebes ipsas ad beneffaciendum dicto hospitalis, salubribus, monitis et exortacionibus inducendo. Sperantes ab illo premium qui in centuplum remunerat omne bonum. Nos enim super hoc a dicto domino nostro archiepiscopo specialem potestatem habentes de omnipotentis Dei misericordia beatorum quoque Petri et Pauli apostolorum eius auctoritate ac Valerii /confessorunt $\backslash$ anthistitis ecclesie Cesarauguste meritis confidentes omnibus et singulis Christi fidelibus vere penitentibus et confessis qui dicto hospitali seu eius hospitalaris procuratori vel nuncio presentibus comito manus suas porrexerint quomodolicet adiutrices triginta dies de iniunctis sibi legitime penitenciis per graciam Sancti Spiritus misericorditer in Domino relaxamus. Presentibus post trienium minime valituris. Datum Turolii, die XVIII ${ }^{\text {a }}$ decembris anno a Nativitate Domimi millesimo $\mathrm{CCCC}^{\circ} \mathrm{VI}^{\circ}$.

7.

27, febrero, 1408. Daroca.

Juan Boecio, canónigo del vicario general, en nombre del arzobispo García Fernández de Heredia, concede a los jurados y hombres buenos del lugar de San Martín del Río el hospital de dicho lugar para que lo reparen, administren y acondicionen una estancia para el descanso de los pobres.

ADZ, RAC, t. VI (1407-1408), f. 314v.

/f. 314v/ Concessio hospitalis de Sancti Martin del Rio.

Johannes Boeci, canonicii Vicensis ac plebanus de Martino, vicarius generalis, in specialibus et temporalibus reverendisimi in Christo pateis et domini domini Garsia miseratione divina archiepiscopis Cesarauguste, venerabilis et discretis concilis jurates et probiis hominibus loci Sancti Martini del Rio, riparie de Xiloqua, Cesarauguste diocesis, salutem in Domino. Cum nos in ecclesia dicti loci et in periplo eiusdem visitacionis officium exercendo inter coram invenerimus quod hospitale dicti loci in quo reciperi et hospitari consuererunt pauperes Ihesu Christi, confrontatum ab una parte cum orto Juliani Petri, et ab alia cum orto dompno Mathee Sancii Binas, uxor dompni Petri de Linyan, scutiferi quondam, ab alia parte cum domibus Petri Didaci de Valdiveiento, et ab alia cum via publica, et ab alia cum cequia de Gavarda propter deffectum reparacionis et materie vetustate corruit ex toto successibus ruinosis propterea volentes quantum possumus Christi pauperibus providem auctem officii quo fungimur in hac parte damus et concedimus vobis /perpetuol dictum hospitale reperandum, tenendum, possidendum gubernandum, regendum et administrandum cum possesionibus et juribus cum overe tamen et condicione sequenti ludelicet, quod habeatis tenere in dicto hospitali unam domum sive palacium aut cameram cum uno lecto ornato randis condecenter in quo Christi pauperes ad dictum hospitale declinantes possint recipi quiestere et dormire, et cum huiusmodi overe tamen vos et vestri qui pro tempore erunt dictum hospitale cum suis domibus pertinenciis possessionibus et juribus universis regatis, teneatis, possidatis, gubernetis et administretis et inde ad libitum disponetis et ordinetis, scitra tamen alienacionem et vendicionem dicti hospitalis aut aliquarum possessionum seu jurium eiusdem. Et nos Michael de Tudela et Ferdinandus de Albarrazin, jurati annuales dicti loci Sancti Martini, per nos et succesores nostros juratos dicti loci qui pro tempore erunt ac nomine etiam totius concilii dicti loci et etiam ago Julianus Petri d'Albarrazin, vicinus prefati loci ac procurator dicti concilii, constitutus cum publico instumento acto in dicto loco XVIII ${ }^{\mathrm{a}}$ die mensis octobris anno a Navititate Domini $\mathrm{M}^{\circ} \mathrm{CCCC}^{\circ} \mathrm{VII}^{\circ}$ et clauso per Jo- 
hannes de Alaymanya, vicinum de Baguena, de auctoritate illustrisimi domini regis notarium publicum per totum regnum Aragonum, predictam concessionem et donacionem recipimus et acceptamus a vobis dicto domino vicario generali et dictum hospitale reparare, regire, gubernare dictum lectum manutencione et alia omnia et singula supradicta convenimus et promittimus ac nos obligamus perpetuo pro Dei servicio inviolabiliter observare in quorum testimonium nos domus vicarius generalis presentes fieri a sigillo dicti domini archiepiscopi in pendenti jussimus comuniri. Datum Daroce, die XXVII ${ }^{a}$ mensis febroarii anno a Nativitate Domini $\mathrm{M}^{\circ} \mathrm{CCCCVIII}{ }^{\circ}$.

\section{8.}

21, julio, 1408. Zaragoza.

El arzobispo García Fernández de Heredia, ante la mala administración del hospital de Burbáguena, insta a los jurados y hombres buenos del lugar para reconstruir y dotar adecuadamente el mismo, las habitaciones anexas a la iglesia o la capilla de San Miguel, para que pobres y peregrinos tengan un sitio donde albergarse.

ADZ, RAC, t. VI (1407-1408), f. 349r.

/f. 349r/ Licenciam de Burvaguena.

Garsias et etc., venerabilis et discretis juratis et probiis hominibus loci de Burvaguena, nostre diocesis, salutem in Domino. Cum ut precepimus hospitale anticum dicti loci vicio vetustatis materie et propter malam administracionem corruerit funditus successibus ruinosis et non possint ibi recoligi pauperes Ieshu Christi, propterea suplicato nobis vestri ex parte super hoc provideri, vobis edifficandi et costruendi de novo hospitale, sive domos, aut cameras contiguas ecclesie sive capelle Santi Nicholai dicti loci in quo seu quibus recipi valeant pauperes, peregrini et alii ibidem convenientes, illudque seu illas preficendi opere congenenti, nec non parandi lectos et alia necessaria et oportuna licenciam et facultatem plenaria presentibus impertimur constitutione quamcumque sive provisione in contrarium edita non obstante. Datum Cesarauguste die $\mathrm{XXI}^{\mathrm{a}}$ julii anno a Nativitate Domini $\mathrm{M}^{\circ} \mathrm{CCCC}^{\circ} \mathrm{VIII}^{\circ}$. Videlicet io Boeci.

\section{9.}

21, julio, 1408. Zaragoza.

El arzobispo García Fernández de Heredia concede cuarenta días de indulgencias a quienes ayuden con sus limosnas a la iglesia y hospital de San Fabián y San Sebastián de Teruel.

ADZ, RAC, t. VI (1407-1408), f. 347r.

/f. 347r/ Privilegium Sanctorum Fabiani et Sebastiani Turolii.

Garsias miseracione divina archiepiscopus Cesarauguste. Dilectus in Christo universis et singulis prioribus, archipresbiteris, plebanis, rectoribus et vicariis ceterisque presbiteris curatis per civitatem et diocesis nostram Cesarauguste constitutis, ad quem vel quos presentes pervenerint, salutem in Domino et bonis semper operibus habundare. Tanto vos et etc. Cum itaque Benedictus, procurator, administrator et hospitalarius ecclesie Sanctorum Sebastani et Fabiani civitatis Turolii, nostre diocesis, lator presenciam ad reparacionem dicte ecclesie quod evidenter minatur ruinam in qua dominus nostrum Ihesus Christus nuncis dictorum Sanctorum Martirum multa et diversa miracula operatur et alias necessitates hospitalis eiusdem indegeat Christi 
Aproximación a los hospitales a través de los registros de actos comunes de la Archidiócesis...

fidelium helemosinus et sucursu. Idcirco vobis in virtute sancte hobedientie dicimus et mandamus, quatenus cum dictus procurator ad vos seu ecclesias vestras declinaverit Christi fidelium helemosinas petiturus, presentibus comunitus ipsum benigne recipiatis et caritative tractetis ac permictatis in vestris ecclesiis et parrochiis helemosinas petere et congregatione. Eumque plebibus vobis comissis presentetis plebes easdem ad beneffaciendum eidem salubribus, monitis et exortacionibus inducendo. Sperantes et etc. Nos enim de omnipotentis Dei misericordia beatorum quoque et etc. omnibus et singulis Christi fidelibus vere penitentibus et confessis qui ad reparacionem et necessitatem dicte ecclesie et hospitalis eiusdem manus suas porrexerint quomodolizet adiutrices $\mathrm{XL}^{\mathrm{a}}$ dies de iniunctis sibi legittime penitenciis per graciam Sancti Spiritus misericorditer in Domino relaxamus. Presentibus post quinquenimum minime valituris. Datum Cesarauguste, die $\mathrm{XXI}^{\mathrm{a}}$ julii anno a Nativitate Domino $\mathrm{M}^{\circ} \mathrm{CCCC}^{\circ}$ octavo.

10.

14, enero, 1411. Zaragoza.

El arzobispo García Fernández de Heredia, ante la inexistencia de un hospital para pobres y peregrinos en Muniesa, concede a Simón Acenari, vicario de la iglesia de Cortes de Aragón, una licencia para construirlo.

\section{ADZ, RAC, t. VII (1409-1411), f. 349r-v.}

\section{/f. 349r/ Per hospitali de Muniesa}

Garsias et etc., dilecto in Christo Simoni Acenarii, vicario perpetuo /pro\ecclesie /loci de Cortes, honoris de Huesa nostre diocesis, salutem in Domino. Devotionis vestre sinceritas promeretur, ut illa que salutem anime et honorem persone vestre respiriunt, vobis quantum cum Deo possimus liberaliter concedamus cum itaque in loco de Muniesa dicte diocesis vestris estis oriundus non sit in hospitale, ubi peregrini et Christi pauperes hospitentur, ymo pauperes ipsi, dum illuc declinant vix reperiunt, ubi capud sunt reclinetur et vos devocione motus, inspecto quod ea solum de bonis temporalibus retinentur que pro Christi nomine largiuntur proposuerit de novo hedifficare unum hospitale cum suis lectis, raubis et aliis necessariis ad husum et necessitatem pauperum Ieshu Christi et quia ad hoc non et alius locus ut asservistis magis conveniens quod quonddam ovile sive solare confrontatum ab una parte cum domibus Dominici Calvo et ab alia cum domibus Johannis de Marzen et cum viis publicis, quod secundum dictum vulgare dicebatur antiquitus abbatie, loci predicti, /f. $349 \mathrm{v} /$ licet a $\mathrm{C}^{\mathrm{m}}$ annis scitra vel saltim a memoria hominum ibi abatia seu hedifficium /aliquod $\backslash$ ut asseritur non fuerit, propterea inspecto quod omnia que habet Sancta Maria ecclesia debent ad husum pauperum esse prompta tenore presentis, dictum ovile sive solare profundando, hedifficando et construendo dictum hospitale ad husum et necessitatem /pauperum \et pro recoligendis pauperibus Ihesu Christi /vobis perpetuo prout plenius possumus, concedimus et donamus pura /et। perfecta gratia et irrivocabili donacione, concedentes vobis licenciam plenariam et facultatem quod dictum hospitale ut decentius poteritis, hedefficetis, construatis et perficiatis ad usum tamen hospitalis et necessitatem pauperum Ihesu Christi, mandantes universis et singulis ad quos spectet et presentes pervenerint, quatenus provisionem et gratiam nostram huiusmodi vobis teneant inviolabiler et observent et eidem non presumant ullatenus contrahire. In quorum testimonium presentes vobis fieri et sigillo nostro impendenti iussimus comuniri. Datum Cesarauguste, die XIIII ${ }^{\mathrm{a}}$ mensis januarii anno a Nativitate Domini $\mathrm{M}^{\circ} \mathrm{CCCC}^{\circ}$ undecimo. 
4, abril, 1411. Zaragoza.

El vicario general de la diócesis de Zaragoza comunica a Simón Acenari la obligación de decir misa por las almas de Domingo Serrano y su mujer Benedicta con motivo de sus donaciones testamentarias para el hospital de Muniesa, y además, concede una renta anual de 10 sueldos y 8 dineros jaqueses para el mantenimiento de dicho hospital.

ADZ, RAC, t. VII (1409-1411), ff. 380v-381r.

/f. 380v/ Per quodam hospitali de Muniesa.

Vicarii generalis et etc., dilecto in Christo Simoni Acenarii, presbitero vicario perpetuo ecclesie loci de Cortes, honoris de Huesa, Cesarauguste diocesis, et aliis quos spectet et presentes pervenerint presentibus et futuris et singulis eorum, salutem in Domino. Peticionem nobis oblatam ex parte suscepimus continentem, quod Dominicus Serrano et Benedicta, eius uxor quondam, loci de Muniesa dicte diocesis, pro salute animarum suarum, dimiserunt in suis ultimis testamentis quasdam domos sive quoddam ovile ubi construeretur et edifficaretur hospitale ad recoligendi pauperes Ihesu Christi, et quia jurati et probii homines dicti loci quibus incumbebat omnis dictum hospitale faciendi illud facere non curarunt venerabilis Raymundus Bigores, tunc archidiachonus Sante Engracie et officialis Cesarauguste in deffectum eorum et voleus providere quod anime dictorum testatorum ex dictam ordinacione aliquod suffragium consequerentur, comisit vobis et Ferrario de la Reula, quondam vicario ecclesie dicti loci quod dictum ovile tributaretis perpetuo, plus offerenti seu offerentibus, in eodem et ex tributo inde habendo celebrarentur misse pro animabus dictorum testatorum, cuius quidem comissionis vigore, vos una cum dicto quondam vicario dictas domos sive ovide perpetuo ut asseritur tributastis veris, quia ut percepimus in dicto loco queddam hospitale ad husum Christi pauperum noviter est constructum et est consonum racioni quod census sive tri-/f. 381r/ butum dictarum domorum sive ovilis serviat et convertatur in husu ad quem per dictos testatores extitit ordinatum cum eorum voluntas quod lege merito sit habenda, proptea supplicato nobis super hoc provideri volentes tam saluti animarum dictorum testatorum quod dicto hospitali et Christi pauperibus providere tenore presentis auctem officii quo fungimur in hac parte perpetuo providemus, ordinamus, decretamus, volimus et mandamus quod decem solidum et octo denarii jaccensis annuales, rendales et perpetuales qui habentur ac dantur et solvuntur annuatim ratione dictarum domorum, sive ovilis, per detinentes, sive possidentes, illud presents et qui quod temporem erunt dicto hospitali, ac eius et pauperum Christi ibi convieni encium necessitatibus, reparacioni et husibus perpetuis temporibus aplicentur et eidem hospitali seu eiusdem administratori dicti possidentes sive detinentes presents et postire toneantur etc. integre et effectualiter respondere, ordinacione celebra dictarum missarum que in hoc casu non vendicat sibi locum in aliquo, non obstante inquorum et etc. Datum Cesarauguste, die IIII aprilis anno a Nativitate Domini $\mathrm{M}^{\circ} \mathrm{CCCC}^{\circ}$ undecimo.

\section{Referencias bibliográficas}

ARCARAZO, L. A. (2010), La asistencia sanitaria pública en el Aragón rural entre 1673-1750: las conducciones sanitarias de Barbastro, Zaragoza, IFC. 
Aproximación a los hospitales a través de los registros de actos comunes de la Archidiócesis...

ARCARAZO, L. A., y LORÉN, M. a . P. (2000), El Santo Hospital de San Julián Mártir y Santa Lucía y otros Hospitales de Barbastro, Barbastro, Centro de Estudios del Somontano de Barbastro.

BALOUP, D. (2003-2004), «La muerte y la penitencia en la predicación de las indulgencias en Castilla a finales de la Edad Media», Edad Media. Revista de Historia, $\mathrm{n}^{\circ}$ 6, pp. 61-89.

BAQUERO, A. (1952), Bosquejo histórico del Hospital Real y General de Nuestra Señora de Gracia de Zaragoza, Zaragoza, IFC.

BLASCO, A. (1989-1990), «Instituciones sociorreligiosas judías de Zaragoza (siglos XIV-XV). Sinagogas, cofradías, hospitales», Sefarad, no 49/2, pp. 227-236 y n 50/1-2, pp. 3-46 y 265-288, respectivamente.

BLASCO, M. (2014), Los hospitales rurales de Aragón en el último tercio del siglo XVIII, Universidad de Zaragoza (tesis doctoral inédita).

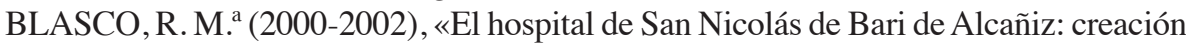
y función social de una institución centenaria», Teruel, n 88-89-II, pp. 139-168.

- (2008), El Hospital de San Nicolás de Bari de Alcañiz (1418-1936), Alcañiz, Hospital de Alcañiz.

BUESA, D. (1991), «La diócesis de Zaragoza, aproximación a su historia» en M. ${ }^{a}$ M. Agudo (coord.), El espejo de nuestra historia: la diócesis de Zaragoza a través de los siglos, Zaragoza, Arzobispado de Zaragoza, pp. 29-68.

BUOMPADRE, M. ${ }^{a}$ L. (2000), «Aproximación a la historia de los pobres en la sociedad aragonesa bajomedieval», Studium: Revista de Humanidades, $\mathrm{n}^{\circ}$ 17, pp. 67-88.

BURETA, I. (2003), «Báguena en el siglo XV. Datos para su historia», Xiloca, $\mathrm{n}^{\circ} 31$, pp. 15-53.

CASTILLÓN, F. (1995), «Parroquias desaparecidas del Medio-Bajo Cinca y de la Litera», Aragonia Sacra, no 10, pp. 93-126.

CUELlA, O. (2006), Bulario Aragonés de Benedicto XIII (I): la Curia de Aviñón (1394-1403), Zaragoza, IFC.

- (2011), Bulario Aragonés de Benedicto XIII (1394-1423) (V): la Curia Cesaraugustana, Zaragoza, IFC.

DEL CAMPO, A. (2001-2002), «Aproximación a un mapa devocional de Zaragoza en el siglo XIV», Turiaso, n 16, pp. 87-143.

DOLSET, J. (1955), «El hospital de Nuestra Señora de Gracia de Zaragoza», Zarago$z a, \mathrm{n}^{\circ} 1, \mathrm{pp} .13-19$.

DOMINGO, T. (2001), «Documentos privados del siglo XII del hospital de peregrinos de Santa Cristina de Somport en el Archivo Capitular de la Seo de Zaragoza», Memoria ecclesiae, $\mathrm{n}^{\circ} 19$ (Peregrinacion y santuarios en los Archivos de la Iglesia; Santoral Hispano-mozárabe en las Diócesis de España. Actas del XV Congreso de la Asociación de Archiveros de la Iglesia en España, Santiago de Compostela, 1999), pp. 285-313. 
DURIÁN, A. (1986), El hospital de Somport entre Aragón y Bearn (siglos XII y XIII), Zaragoza, Guara Editorial.

ESPARZA, J. M. a (2001-2002), «Hospitalidad al peregrino dentro de la diócesis de Zaragoza entre los años 1771 al 1807», Revista de Historia Jerónimo Zurita, n ${ }^{\circ}$ 76-77, pp. 91-128.

FALCÓN, Mª I. (1980), «Sanidad y beneficencia en Zaragoza en el siglo XV», Aragón en la Edad Media, n 3 , pp. 183-226.

FERNÁNDEZ, A. (2000), El Hospital Real y General de Nuestra Señora de Gracia en el siglo XVIII, Zaragoza, IFC.

GALLENT, M. (1996), «Historia e historia de los hospitales», Revista d'historia medieval, $\mathrm{n}^{\circ} 7$, pp. 179-191.

GARGAllO, A. J. (1996), El Concejo de Teruel en la Edad Media, 1177-1327, vol. I, Teruel, Instituto de Estudios Turolenses.

GEREMEK, B. (1986), La piedad y la horca, Madrid, Alianza Editorial.

GIL, A. (1995), «Una visita pastoral del siglo XV», Aragonia Sacra, n 10, pp. 199228.

GIMENO, J. (1908), La Casa de Locos de Zaragoza y el Hospital de Nuestra Señora de Gracia: apuntes históricos 1425-1808-1908, Zaragoza, Librería Cecilio Gasca. GOÑI, J. (1965), Catálogo del Archivo Catedral de Pamplona. Tomo I (829-1500), Pamplona, Institución «Príncipe de Viana».

IRANZO, M. ${ }^{\text {a }}$ T. (1995), «Asistencia pública y segregación social: el Hospital de leprosos en Huesca siglos XI-XIV» en Homenaje a Antonio Durán Gudiol, Huesca, Instituto de Estudios Altoaragoneses, pp. 467-482.

- (1997), «Pobreza, enfermedades y símbolos del poder señorial en Híjar. El Hospital de la Santa Cruz, 1300-1312», Aragón en la Edad Media, n 13, pp. 105-124.

ITURBE, G. y LORENZO, I. (2010), El siglo XV en Muniesa (Teruel) y su entorno (1367-1503), Teruel, Centro de Estudios de Miguel de Molinos.

KIVIHARJU, J. (1991), Cartulario del hospital de Santa Cristina de Somport, Helsinki, Suomalainen Tiedeakatemia.

- (2004), Colección diplomática del hospital de Santa Cristina de Somport I. Años 1078-1304, Helsinki, Academia Scientiarum Fennica.

LASARTE, J. A. (2002), Libro primero de los Registros de Actos Comunes y Órdenes en el Archivo Diocesano de Zaragoza (trabajo inédito).

- (2003), Índice de los Registros de Actos Comunes y Órdenes correspondientes al pontificado de don García Fernández de Heredia (1383-1411) (trabajo inédito).

LOZANO, A. (1981), «El Archivo Diocesano de Zaragoza», en Estado actual de los archivos con fondos aragoneses. I Jornadas de Archivos (Zaragoza, 26-28 de febrero de 1980), Madrid, Ministerio de Cultura, pp. 61-66.

MARCO, M. ${ }^{\text {a }}$ P. (1976-1977), «Las iglesias de Daroca en el último tercio del siglo XIV según la visita pastoral de 1387», Revista de Historia Jerónimo Zurita, $\mathrm{n}^{\circ}$ 29-30, pp. 97-127. 
Aproximación a los hospitales a través de los registros de actos comunes de la Archidiócesis...

MIGUEL, I. (1997), «Labor benéfica y hospitalaria de Don Hernando de Aragón, arzobispo de Zaragoza (1539-1575)», Memoria ecclesiae, $\mathrm{n}^{\circ} 11$ (Beneficencia y hospitalidad en los Archivos de la Iglesia; Santoral Hispano-mozárabe en las Diócesis de España. Actas del XI Congreso de la Asociación de Archiveros de la Iglesia en España, Valencia, 1995), pp. 115-128.

MONTERDE, C. (2008), «Las ordinaciones del Hospital de Nuestra Señora de Gracia de Zaragoza establecidas por don Alfonso de Aragón, Arzobispo de Zaragoza y Lugarteniente General del Reino», Aragón en la Edad Media, n 20, pp. 505-528.

MUÑOZ, J. (1944), «Privilegios a favor del Hospital Provincial de Nuestra Señora de Gracia de Zaragoza», Anuario de Derecho Aragonés, n 1, pp. 143-166.

NAVARRO, G. (2000), «El hospital de Santa María de Villaespesa y de San Juan Bautista en la ciudad de Teruel a través de los actos notariales de Alfonso Jiménez (1481-1518)», Aragón en la Edad Media, n 16, pp. 565-590.

- (2001), «Fuentes para la historia de la pobreza y la marginación» en Agustín Ubieto Arteta (ed.), II Jornadas de Estudios sobre Aragón en el umbral del siglo XXI (Alcorisa, 17-19 de diciembre de 1999), Zaragoza, Instituto de Ciencias de la Educación y Universidad de Zaragoza, pp. 337-346.

ONA, J. L. y CALASTRENC, C. (2009), Los hospitales de Benasque y Bañeras de Luchón. Ocho siglos de hospitalidad al pie del Aneto, Benasque, Fundación Hospital de Benasque.

PÉREZ, C. (2013), «Los grandes hospitales urbanos en Aragón en el siglo XV: Nuestra Señora de la Esperanza en Huesca y Nuestra Señora de Gracia en Zaragoza» en Assistenza e solidarietà in Europa Secc. XIII-XVIII, Atti della "Quarantaquattresima Settimana di Studi» 22-26 aprile 2012 a cura di Francesco Ammannati, Florencia, Firenze University Press, pp. 291-305.

PUEYO, P. (1989), «Aproximación a una tipología documental de los registros de actos comunes de la Diócesis de Zaragoza durante el arzobispado de Pedro de la Jugie (1345-1347)», Aragón en la Edad Media, nº 8, pp. 523-536.

- (1991), «El Registro de Actos Comunes del Arzobispado de Zaragoza. Pedro de la Jugie (1346-1347)», Aragón en la Edad Media, nº 9, pp. 269-312.

- (1993), «La Peste Negra en la Diócesis de Zaragoza: el registro de actos comunes del arzobispo Guillermo de Agrifolio (1348-1350)», Aragón en la Edad Media, ${ }^{\circ}$ 10-11, pp. 705-736.

- (1997), «Litterae "pro captivis" en los registros de Pedro de la Jugie y Guillermo de Aigrifeuille, arzobispos de Zaragoza (años 1346-1349)», Memoria ecclesiae, $\mathrm{n}^{\circ}$ 11 (Beneficencia y hospitalidad en los Archivos de la Iglesia; Santoral Hispanomozárabe en las Diócesis de España. Actas del XI Congreso de la Asociación de Archiveros de la Iglesia en España, Valencia, 1995), pp. 355-366.

- (2000), «"Litterae acaptandi” concedidas por el arzobispo de Zaragoza Dalmau de Mur en los años 1433-1440», en M. ${ }^{a}$ T. Ferrer y J. Mutgé (eds.), De l'esclavitud a la llibertat: esclaus $i$ lliberts a l'edat mitjana: actas del colloqui internacional 
celebrat a Barcelona, del 27 al 29 de maig de 1999, Barcelona, Institució Milà i Fontanals, pp. 401-431.

PUEYO, P. (2000), «Licencias para pedir limosnas, con o sin indulgencias, otorgadas por los arzobispos de la diócesis de Zaragoza en la segunda mitad del siglo XIV», Aragón en la Edad Media, n 16, pp. 683-708.

- (2001), «El documento eclesiástico: la cancillería episcopal» en A. Ubieto (ed.). III Jornadas de Estudios sobre Aragón en el umbral del siglo XXI (Caspe, 15-17 de diciembre de 2000), Zaragoza, Instituto de Ciencias de la Educación y Universidad de Zaragoza, pp. 701-713.

- (2003), «El arzobispado de Zaragoza en la segunda mitad del siglo XIV y el clero extradiocesano», en El món urbà a la Corona d'Aragó del 1137 als decrets de Nova Planta: XVII Congrés d'Història de la Corona d'Aragó (Barcelona, Poblet, Lleida, 7 al 12 de desembre de 2000), vol. 3, Barcelona, Universidad, pp. 769-788.

- (2005), «El clero extradiocesano en el arzobispado de Zaragoza a principios del siglo XV», Anuario de estudios medievales, $\mathrm{n}^{\circ} 35-2$, pp. 799-862.

- (2008), «Nombramientos de notarios por los arzobispos de la Diócesis de Zaragoza (1346-1411)», Aragón en la Edad Media, n 20, pp. 635-660.

- (2011), «Documentación eclesiástica y vida cotidiana. La práctica devocional en la diócesis de Zaragoza durante el arzobispado de García Fernández de Heredia (1383-1411)», Archiv für Diplomatik: Schriftgeschichte. Siegel-und Wappenkunde, $n^{\circ} 57$, pp. 315-352.

RODRIGO, M. ${ }^{a}$ L. (1995), «Poder municipal y acción benéfico-asistencial. El concejo de Daroca, 1400-1526», Aragón en la Edad Media, n 12, pp. 287-318.

ROYO, J. R. (1993), «Noticias históricas sobre las parroquias de la Archidiócesis de Zaragoza vinculadas a las órdenes monásticas», Revista de Historia Jerónimo Zurita, 67-68, pp. 43-63.

- (2000), «Datos para la historia del arte en el registro de decretos de 1581-1611 del Archivo Diocesano de Zaragoza», Memoria ecclesiae, $\mathrm{n}^{\circ} 16$ (Arte y Archiveros de la Iglesia en España; Santoral Hispano-mozárabe en las Diócesis de España. Actas del XIV Congreso de la Asociación de Archiveros de la Iglesia en España, Barcelona, 1998), pp. 537-549.

RUBIO, A. (1997), «Beneficencia y hospitalidad en la ciudad de Valencia durante la Baja Edad Media según las fuentes archivísticas», Memoria ecclesiae, nº 10 (Beneficencia y hospitalidad en los Archivos de la Iglesia; Santoral Hispano-mozárabe en las Diócesis de España. Actas del XI Congreso de la Asociación de Archiveros de la Iglesia en España, Valencia, 1995), pp. 15-60.

RUBIOLO, M. (2004), «La historia de la pobreza medieval. Algunas notas para su renovación», Temas medievales, $\mathrm{n}^{\circ}$ 12, pp. 193-206.

SÁNCHEZ, J. (1974), «Cofradías, hospitales y beneficencia en algunas diócesis del valle del Duero, siglos XIV y XV», Hispania, n 126 , pp. 5-52.

SERRANO, A. (2002-2003), «Episcopologio de Zaragoza», Aragonia Sacra, nº 1617, pp. 197-246. 
Aproximación a los hospitales a través de los registros de actos comunes de la Archidiócesis...

SERRANO, A. (2004-2005), «Índice de los episcopologios de las diócesis aragonesas y apéndice al episcopologio de Zaragoza», Aragonia Sacra, nº 18, pp. 87-97.

SUÁREZ, A. (1997), «Hospitalidad y beneficencia en San Isidoro de León: servicios y cargos desempeñados durante los siglos XII al XVI», Memoria ecclesiae, $\mathrm{n}^{\circ} 10$ (Beneficencia y hospitalidad en los Archivos de la Iglesia; Santoral Hispano-mozárabe en las Diócesis de España. Actas del XI Congreso de la Asociación de Archiveros de la Iglesia en España, Valencia, 1995), pp. 303-326.

UBIETO, A. (1966), «Los primeros años del Hospital de Santa Cristina de Somport», Príncipe Viana, $\mathrm{n}^{\mathrm{o}}$ 104-105, pp. 267-276.

- (1983), «Pobres y marginados en el primitivo Aragón», Aragón en la Edad Media, $\mathrm{n}^{\circ} 5$, pp. 7-22.

- (1983), Historia de Aragón: Divisiones administrativas, Zaragoza, Anubar.

VILLAGRASA, R. (2013-2014), La red de hospitales en el Aragón medieval (ss. XII$X V)$, Universidad de Zaragoza (trabajo final de máster inédito, dirigido por los Dres. Germán Navarro y Concepción Villanueva).

ZUBIRI, F. (1972), Consideraciones históricas sobre algunos hospitales de Zaragoza y su provincia, Zaragoza, IFC. 

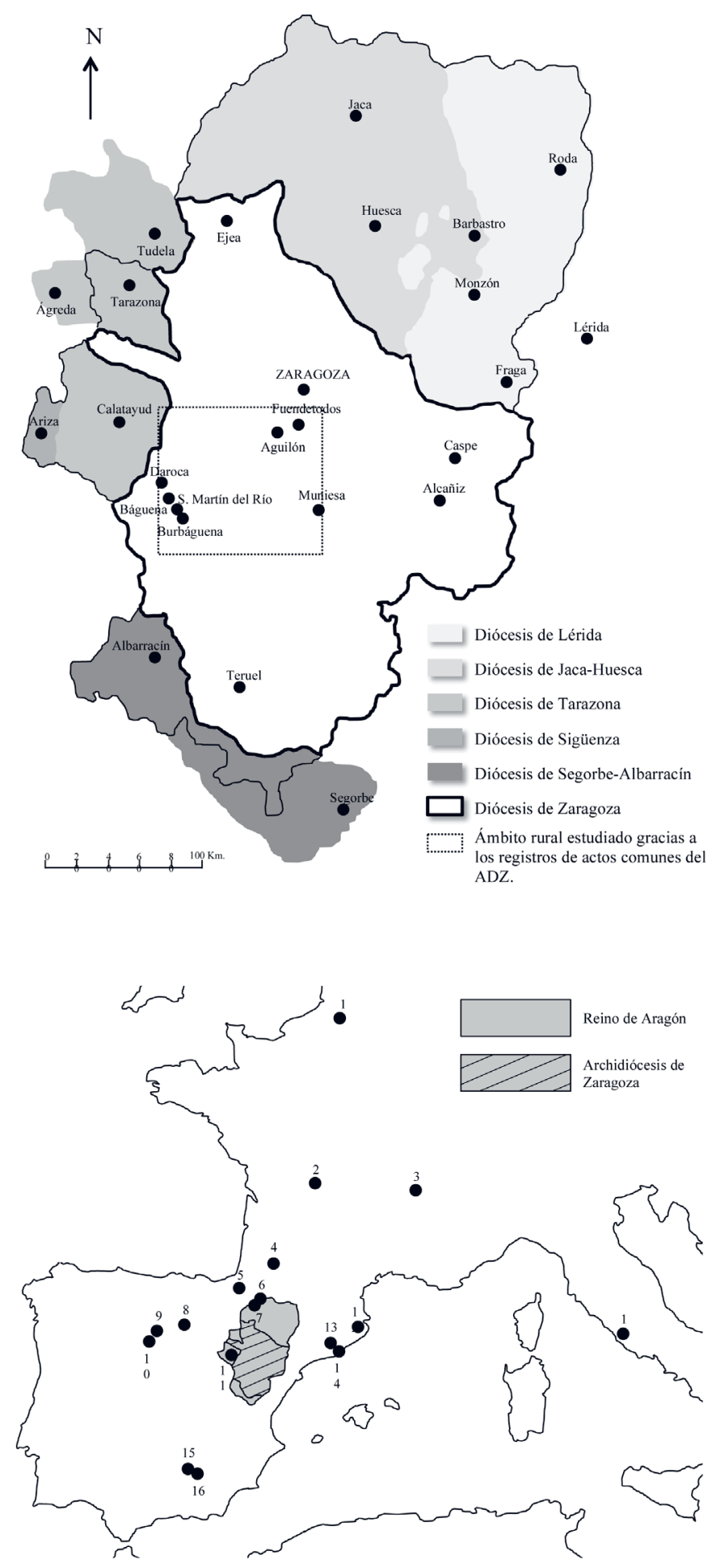

MAPA 1. La organización episcopal sobre el reino de Aragón
Base cartográfica: CORRAL, J. L. «Las diócesis aragonesas en la Edad Media», en Atlas de Historia de Aragón, IFC, mapa 49 [en red].

MAPA 2. Instituciones

hospitalarias de fuera de la archidiócesis zaragozana mencionadas en los registros de actos comunes del Archivo Diocesano de Zaragoza. 